\title{
Review Article \\ The Food Additive Polyglycerol Polyricinoleate (E-476): Structure, Applications, and Production Methods
}

\author{
Josefa Bastida-Rodríguez \\ Department of Chemical Engineering, University of Murcia, Campus de Espinardo, 30100 Murcia, Spain \\ Correspondence should be addressed to Josefa Bastida-Rodríguez; jbastida@um.es
}

Received 27 September 2012; Accepted 4 December 2012

Academic Editors: M. Assael, Z. Fang, A. Gil, F. Lefebvre, J. Subrt, and J. E. Ten Elshof

Copyright (c) 2013 Josefa Bastida-Rodríguez. This is an open access article distributed under the Creative Commons Attribution License, which permits unrestricted use, distribution, and reproduction in any medium, provided the original work is properly cited.

\begin{abstract}
The food additive named polyglycerol polyricinoleate (PGPR) and identified with the code E-476 (PGPR) is used as emulsifier in tin-greasing emulsions for the baking trade and for the production of low-fat spreads. However, the main application of PGPR is in the chocolate industry, where, besides its action as an emulsifier, it also has important properties as a viscosity modifier and thus improves the moulding properties of the molten chocolate. An additional property of PGPR in chocolate is its ability to limit fat bloom. Known chemical methods for preparing this emulsifier involve long reaction times and high operating temperatures, which adversely affect the quality of the final product leading to problems of coloration and odors that could make it inadvisable for the food industry. As an alternative, the enzymatic synthesis of PGPR by the catalytic action of two lipases has been developed. The enzymes act in mild reaction conditions of temperature and pressure, neutral $\mathrm{pH}$, and in a solvent-free system, which makes the process environmentally friendly and avoids side reaction, so that the product has a higher purity and quality.
\end{abstract}

\section{Food Additives}

Food additives have been developed over the years to meet the needs of food production, as making foods on a large scale is a very different task to making them in the kitchen at home. Additives are needed to ensure processed food remains in a good condition throughout its journey from the factory to the shop and to the consumer at home. Some are so essential that they are even used in organic foods [1-3].

In the broadest of terms, food additives are substances intentionally added to food either directly or indirectly with one or more of the following purposes [4]:

(1) to maintain or improve nutritional quality;

(2) to maintain product quality and freshness;

(3) to aid in the processing or preparation of food;

(4) to make food more appealing.

On the other hand, food additives may only be authorized if $[4]$
(1) there is a technological need for their use;

(2) they do not mislead the consumer;

(3) they present no hazard to the health of the consumer.

The use of food additives must always be labelled on the packaging of food products by their category (antioxidant, preservative, colour, etc.) with either their name or E number. In the United States, food additives are regulated by the Food and Drug Administration. Two sections of the regulations govern their use: substances affirmed as GRAS, that is, Generally Recognized as Safe, (21CFR184) and Direct Food Additives (21CFR172). Substances that have been affirmed as GRAS usually have less stringent regulations attached to their use. However, Food and Drug Administration Standards of Identity may preclude their use in certain standardized foods. In comparison, Direct Food Additives may be allowed only in certain specific foods at low maximum allowable levels. The method of manufacture and analytical constants may also be defined. 
The European Community (EC) regulates food emulsifiers in an analogous fashion to United States regulations, identifying the additives with $\mathrm{E}$ numbers. Specific regulations, however, must be consulted before food products are designed for international markets. For example, polyglycerol esters up to a degree of polymerization of 10 are widely accepted in the United States. For the EC, this value may not exceed 4. Standards of Identity may also differ significantly. Other countries, which have not formed trading communities, may have regulations, which are unique [5-7].

The food additive functional classes are based on the Codex Class Names and the International Numbering System (INS) for Food Additives (CAC/GL 36-1989). There are four general categories of food additives: nutritional additives, processing agents, preservatives, and sensory agents. These are not strict classifications, as many additives fall into more than one category [8].

(1) Nutritional additives. They are utilized for the purpose of restoring nutrients lost or degraded during production, fortifying or enriching certain foods in order to correct dietary deficiencies or adding nutrients to food substitutes.

(2) Processing agents. These additives are added to foods in order to aid in processing or to maintain the desired consistency of the product.

(3) Preservatives. They are classified into two main groups: antioxidants (compounds that delay or prevent the deterioration of foods by oxidative mechanisms) and antimicrobials (inhibit the growth of spoilage and pathogenic microorganisms in food).

(4) Sensory agents. Such as colorants (natural or synthetics), flavorings, and sweeteners.

\section{Emulsifiers}

Emulsifiers are essential components of many industrial food recipes (see Table 1), whether they are added for the purpose of water/oil (W/O) emulsification in its simplest form, for textural and organoleptic modification, for shelf life enhancement, or as complexing or stabilizing agents for other components such as starch or protein [9-13].

The main applications of the emulsifiers are based on their ability to interact at the interface between phases. Multiphase systems consist of two or more distinctive phases; systems typical encountered in foods are water-in-oil (W/O), oil-inwater $(\mathrm{O} / \mathrm{W})$, solid-in-oil, gas-in-liquid, gas-, solid- or oilin-water, and so on. These systems are often unstable due to the immiscibility and thus repulsion between the phases. Emulsifiers consist of molecules with ambiphilic properties; that is, part of the structure is of hydrophilic and another of lipophilic nature. In the multiphase systems these emulsifiers will orientate themselves in the position which is favorable with respect to energy, and the emulsifiers will reduce the interfacial tension between the phases in the multiphase system, typically an O/W or W/O system (Figure 1).

The lipophilic moiety of the emulsifier often consists of hydrocarbon chains of fatty acids, and the hydrophilic part

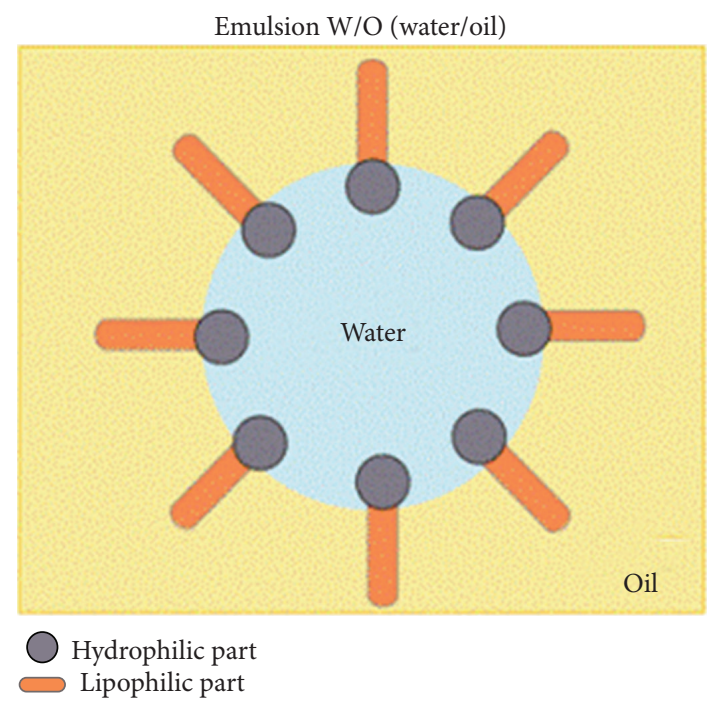

(a)

Emulsion $\mathrm{O} / \mathrm{W}$ (oil/water)

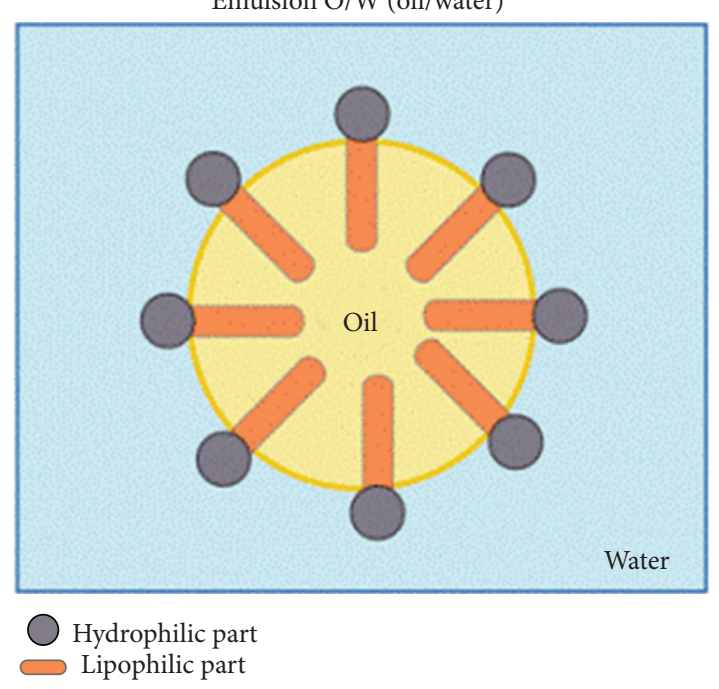

(b)

FIGURE 1: Types of emulsion. http://www.detergentsandsoaps.com/ emulsifiers.html.

TABLE 1: List of foodstuff that contain emulsifiers (http://www .understandingfoodadditives.org/).

\begin{tabular}{lcc}
\hline \multicolumn{3}{c}{ Foods that commonly contain emulsifiers } \\
\hline Biscuits & Toffees & Bread \\
Extruded snacks & Chewing gum & Margarine/low-fat spreads \\
Breakfast cereals & Frozen desserts & Coffee whiteners \\
Cakes & Ice cream & Topping powders \\
Desserts/mousses & Dried potato & Peanut butter \\
Soft drinks & Chocolate coatings & Caramels \\
\hline
\end{tabular}

originates from more polar molecules such as glycerol, lactic acid, citric acid, and polyglycerol. The types and sizes of the lipophilic and hydrophilic moieties determine the functional 
behavior in multiphase systems. An estimate for this relationship is the hydrophilic to lipophilic balance (HLB value), which can be calculated or determined experimentally. A high HLB value (the hydrophilic moiety dominates the emulsifier) typically stabilizes oil-in-water emulsions, whereas low HLB values will lead to water-in-oil type emulsion $[14,15]$.

Emulsifiers include compounds with a completely different chemical structure, and therefore with diverse mechanisms of action, and in turn different effects in dough and bread [16]. Emulsifiers are therefore classified either as ionic or nonionic. The potential for ionization is based on the electrochemical charge of the emulsifiers in aqueous systems. Nonionic emulsifiers (monoglycerides, distilled monoglycerides, epoxylated monoglycerides, and sucrose esters of fatty acids) do not dissociate in water due to their covalent bonds. Ionic emulsifiers may be anionic (diacetyl tartaric acid esters of monoglycerides, sodium stearoyl-2- lactylate) or cationic, but cationic emulsifiers are not used in foods. Amphoteric emulsifiers (lecithin) contain both anionic and cationic groups, and their surface-active properties are $\mathrm{pH}$ dependent $[17,18]$.

\section{Polyglycerol Esters of Fatty Acids}

Polyglycerol esters are nonionic emulsifiers that are allowed for food use in many countries. In addition to the stabilization of emulsions, foams, and dispersions, polyglycerol esters can act as aerating agents, dough strengtheners, rheology modifiers, crystal modifiers, antispattering agents, beverage clouding agents, humectants, solubilizers, or fat substitutes [19]. They have been used as food additives for many years in Europe and America since the 1940s and were approved for food use in the USA, in the 1960s. Due to the innocuous nature of these products, formulators continue to develop technologies that incorporate polyglycerol esters in a widening array of applications. [20-23]. From the legal point of view, food grade polyglycerol esters are divided in two classes: polyglycerol esters of edible fatty acids (E number: E475, also known as "PGFA") and polyglycerol polyricinoleate (E number: E476, also known as "PGPR").

The HLB balance of PGFA depends on the length of the polyglycerol chain (the number of hydrophilic hydroxyl groups present) and the degree of esterification. For example, decaglycerol monostearate has an HLB of 14.5, while triglycerol tristearate has an HLB of 3.6. Intermediate species have intermediate HLB values, and any desired value may be obtained by appropriate blending [15]. Depending upon their HLB, PGFA can act as water-in-oil (W/O) or oil-in-water (O/W) emulsifiers [23].

PGFAs allow a strong interfacial tension reduction between water and a wide variety of oils. In many systems, they have an even better surface activity than glycerol or homologous polyol esters [24, 25]. These esters also form highly stable $\alpha$-gels in water, while gels produced from glycerol monostearate transform with time into a $\beta$-crystal structure called coagel $[26,27]$. The high stability of $\alpha$-gels is a key advantage of PGFA in food applications. Indeed, it leads to better emulsification properties and a higher viscosity of the external water phase, resulting in enhanced stabilization of $\mathrm{O} / \mathrm{W}$ emulsions and foams.

The polyglycerol portion can be prepared by three routes $[15,28]$.

(1) By polymerization of glycerin using strong base as a catalyst. This route leads to several different outcomes.

(a) The polymers of interest, namely, polyglycerin, but with a broad distribution of homologues and significant levels of free glycerin.

(b) The production of cyclic compounds similar to dioxane, which undergo further polymerization.

(c) Dehydration by-products, namely, acrolein, which must be removed by distillation.

(2) By polymerization of glycidol, which leads to linear polyglycerin.

(3) By polymerization of epichlorohydrin, followed by hydrolysis, which also leads to linear polyglycerin. The by-product, sodium chloride, is removed by filtration.

Of these three routes used to produce polyglycerol, the polymerization of epichlorohydrin is the preferred method of manufacture, because polyglycerols obtained by the classical procedures may widely differ in composition. This process is designed to produce high quality products with reduced amounts of cyclic components which have reduced functionality (less hydroxyl groups available). Moreover, this process also allows an excellent control of the reaction, resulting in a narrow oligomer distribution and a minimum batch-to-batch variability [29]. Polymers of epichlorohydrin (or glycidol) are prepared by methods similar to those of other oxirane monomers. The process used is a catalytic ring opening of the oxirane group to form the polymer through an ether linkage between the monomers. Epichlorohydrin is expected to be completely consumed in this polymerization reaction. The final step in any oxirane polymerization is a steam distillation or deodorization step. This deodorization step employs the injection of steam into the reactor at temperatures between $150^{\circ} \mathrm{C}$ and $200^{\circ} \mathrm{C}$ with strong vacuum. Under these conditions, any residual monomer (epichlorohydrin or glycidol) is typically reduced to levels below $1 \mathrm{ppm}$. Specifically for the case of epichlorohydrin polymers, the material must then be hydrolyzed to produce polyglycerol. This is accomplished by base catalyzed reaction with water and excess base, either sodium or potassium hydroxide. If any residual monomer escapes the deodorization step in the polymerization process, it will subsequently be hydrolyzed to glycerin in the hydrolysis step. This is followed by drying, $100^{\circ} \mathrm{C}$ under vacuum, and then filtration of the sodium chloride produced $[28,29]$.

The polyglycerol backbone is then esterified to varying extents, either by direct reaction with a fatty acid or by interesterification with a triglyceride fat. Again, the number of acid groups esterified to a polyglycerol molecule varies around some central value, so an octaglycerol octaoleate 
really should be understood as an (approximately octa)glycerol (approximately octa)-oleate ester. By good control of feedstocks and reaction conditions, manufacturers manage to keep the properties of their various products relatively constant from batch to batch [15].

PGFAs are preferred emulsifiers in baked products due to a variety of properties including enhanced volume and shelf life of yeast dough. They can also act as whipping emulsifiers with improved texture, water binding, and taste in fine baked goods [30]. The most popular food grade PGFAs are polyglycerol monostearates. When mixed with water, these emulsifiers form highly stable $\alpha$-gels exhibit $\alpha$-tending properties. These esters are of special interest, for example in sponge cake technology, where they lead to an optimal stabilization of the batter and a more uniform foam structure (Figure 2). $\alpha$ Gels also improve batter rheology and crumb structure (more regular and softer) and enhance starch complexation leading to increased cake shelf life. In addition, PGFAs exhibit higher heat stability than the equivalent glycerides $[31,32]$.

\section{Polyglycerol Polyricinoleate}

Polyglycerol polyricinoleate, PGPR, identified with the code E-476, is manufactured from polymerized glycerol (above described) and polymerized ricinoleic acid. A typical structure of PGPR is shown in Figure 3.

Ricinoleic acid (12-hydroxy-9-cis-octadecenoic acid) is an unsaturated omega-9 fatty acid (see Figure 4) that naturally occurs in mature castor plant (Ricinus communis L., Euphorbiaceae as shown in Figure 5) seeds.

Polymerized ricinoleic acid, also called ricinoleic acid estolides, is obtained by different methods which are discussed below. The chemical structure is shown in Figure 6 .

PGPR is widely known as an excellent water-in-oil emulsifier in the food industry, because it forms very stable emulsions even when the water content is very high, such as $80 \%$ [33-39]. Therefore, PGPR is used as emulsifier in tin-greasing emulsions for the baking trade [40]. Another important application of PGPR is its use as a water-in-oil emulsifier for the production of low-fat spreads. In this case, PGPR can be used alone or blended with monoglycerides to obtain an optimal quality/cost ratio (see Figure 7) [41, 42].

However, the main application of PGPR is in the chocolate industry. It is especially important for chocolate coatings to flow properly during the enrobing process. Cocoa butter is an expensive raw material, and chocolate manufactures prepare low-fat products to use them only for these applications. Adequate flow properties can be achieved by the addition of PGPR (see Figure 8), which improves the flow characteristics of molten chocolate by reducing the "Casson yield value" (which represents the viscosity of chocolate at low shear rate). By contrast, lecithin tends to be used to decrease the "plastic viscosity" (viscosity at high shear rate) of chocolate [23].

Since lecithin and PGPR have complementary rheological properties, they are often used in combination for an optimal control of chocolate rheology [23,43]. This allows a more even coating of confectionary pieces while reducing the consumption of expensive cocoa butter in the recipe. Lowering yield value also improves the release of entrapped

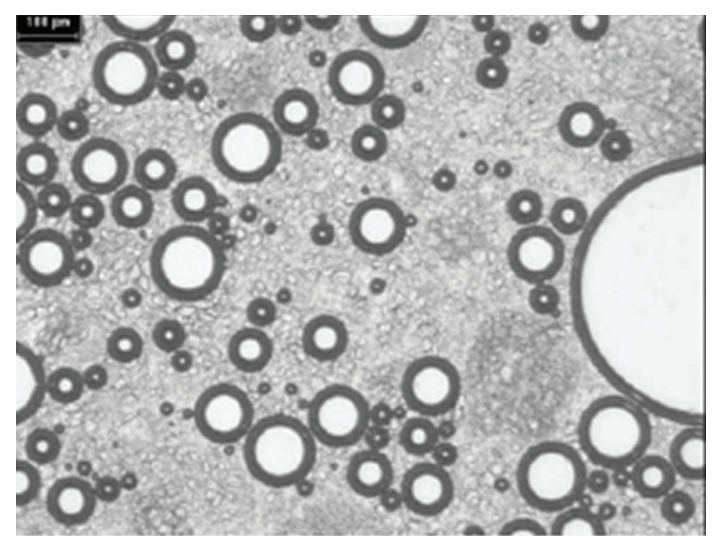

(a)

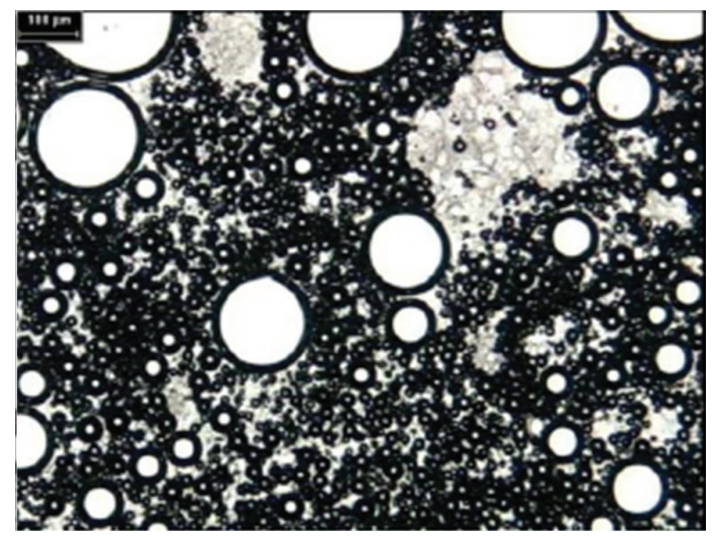

(b)

FIGURE 2: Cake batter with no emulsifier (a) and with $3 \mathrm{~g} / \mathrm{kg}$ polyglycerol monostearate (b) [23].

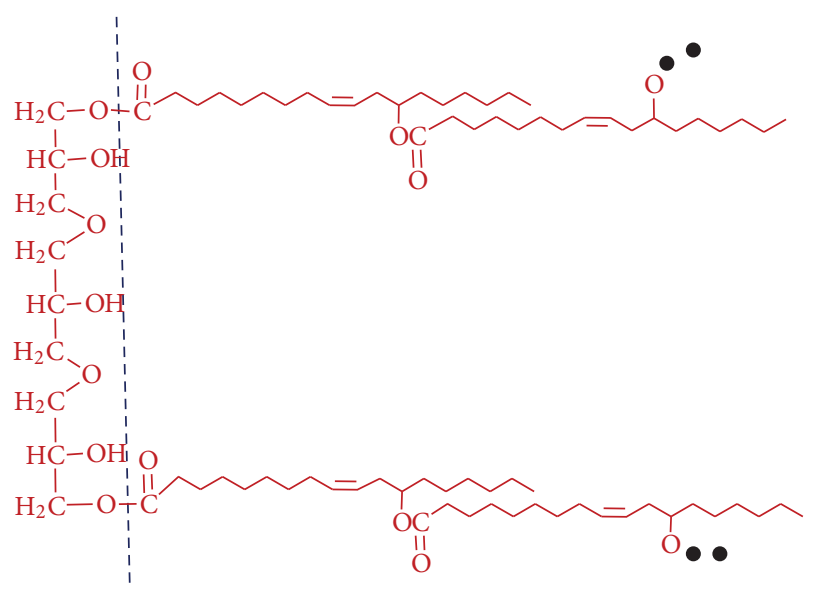

FIGURE 3: Chemical structure of PGPR. Black dots denote polyricinoleic acid chains.

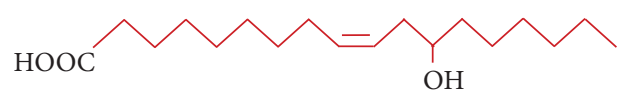

FIGURE 4: Chemical structure of ricinoleic acid. 


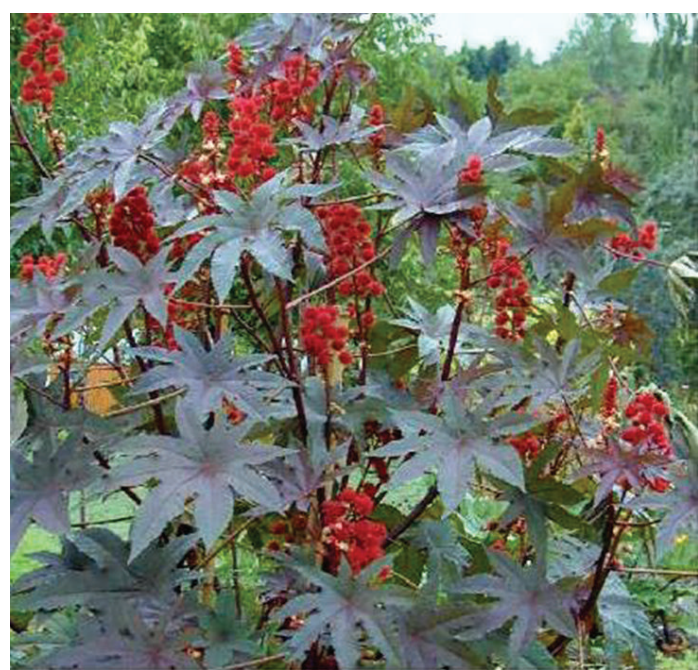

(a)

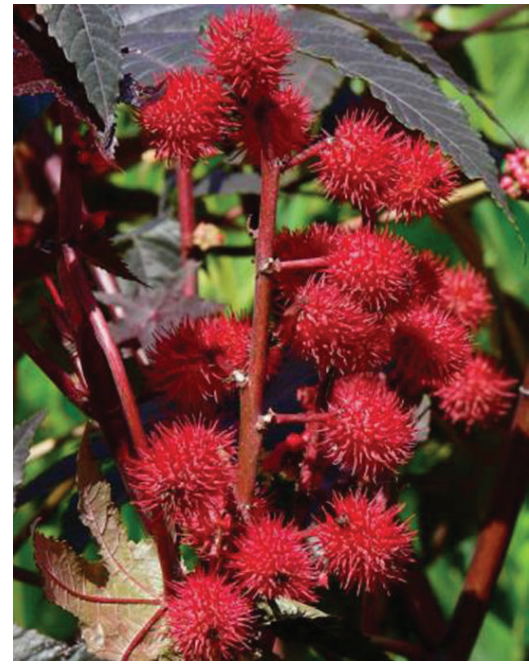

(b)

Figure 5: Photographs of the castor bean plant, Ricinus communis.

air in chocolate, leading to a smoother and more efficient molding and depositing. This is achieved without compromising quality and taste and with cost savings.

An additional property of PGPR in chocolate is its ability to limit fat bloom (see Figure 9). Fat bloom is not always caused by a simple set of circumstances, such as the chocolate becoming wet. Fat bloom is more complicated, and oftentimes it may be more difficult to discover the actual source of the problem. Fat bloom typically appears as lighter color spots on the chocolate. As the name implies, the bloom is composed of fat, in this case the naturally occurring fat that comes from the cacao bean-cocoa butter.

When discussing the reasons for fat bloom, it is important to note that when cocoa butter hardens, it forms crystals. Some of the crystals are stable, but other crystals are not and will actually change form over time. During chocolate manufacturing, a process called tempering is used to ensure that only stable crystals form, while the chocolate hardens.
Fat bloom is caused by the interaction of the various types of crystals or the tempering process (or lack thereof).

If chocolate is not tempered, the unstable forms of cocoa butter crystal will form, most notability the $\beta^{\prime}$ and $\alpha$ forms. After the cocoa butter hardens, these unstable forms will slowly change their forms to the stable $\beta$ form. The $\beta$ crystals are slightly smaller than the $\beta^{\prime}$ or $\alpha$ forms, so that when this transition occurs, the chocolate contracts. The new stable $\beta$ crystals then form, projecting above the surface of the chocolate, visible as bloom.

If the chocolate is stored in a room where the temperature fluctuates near the melting temperature of the stable $\beta$ crystals, two additional types of fat bloom may form. In the first, some of the $\beta$ crystals melt. When they recrystallize, they recrystallize slowly, since the ambient temperature is close to that of the chocolate. This allows the crystals to grow much larger than the original small, compact crystals. In addition to projecting above the surface of the chocolate, these larger crystals may displace cocoa butter, forcing it to the surface.

The second type of bloom is created when the crystals have softened instead of melted. It is during this period that cocoa butter that has slightly melted migrates toward the surface. When it breaks the surface, it pools ever so slightly, and when it cools the cocoa butter appears as spots.

Many people are surprised to learn that fat bloom also occurs in cocoa powder. Cocoa powder contains between $12-20 \%$ cocoa butter. Since some cocoa butter is present, it must be tempered during manufacturing, just as chocolate is. Cocoa powder that has been improperly tempered or undergone temperature fluctuations may cause bleaching of the cocoa powder and may cause clumping, as the cocoa butter helps the particles of the cocoa powder adhere to each other. As with chocolate, when bloom occurs it does not affect the edibility of the cocoa powder but may have an aesthetic impact.

Studies on fat bloom indicate that the bloom consists of large, single cocoa butter crystals or collections of crystals of the stable $\beta$ form of cocoa butter. Other forms of cocoa butter crystals are not present in fat bloom.

Fat blooming actually occurs in a third process. This case affects not so much the chocolate industry directly but the ancillary confectionary industry. When chocolate is used to coat nuts or fillings that contain oils or fats (such as nut butters) that are incompatible with chocolate, the oils may actually seep into or through the chocolate over time. This is called fat migration. As the oils displace the cocoa butter, cocoa butter may sweep onto the surface of the piece of confectionary and recrystallize as bloom. When this occurs, the manufacturing process needs to be examined, or the confectionary needs to be reformulated [44-47].

PGPR is also claimed to increase chocolate's tolerance to the thickening effect caused by small quantities of water, sometimes introduced during enrobing operations [23].

The safety of PGPR consumption has been widely studied. PGPR has been used continuously in greasing emulsions since 1952, following short-term rat feeding trials undertaken in 1951. It was also first used in chocolate couverture in the UK in 1952. During 1952 and 1953, 4.5 tons were used in 1500 


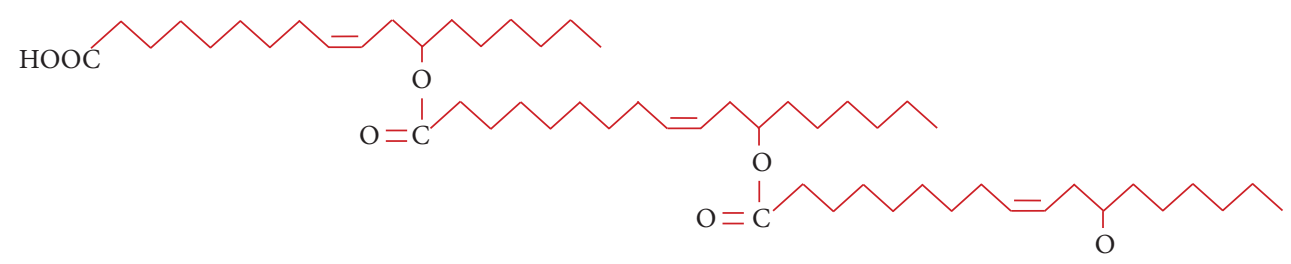

FIGURE 6: Chemical structure of polyricinoleic acid.

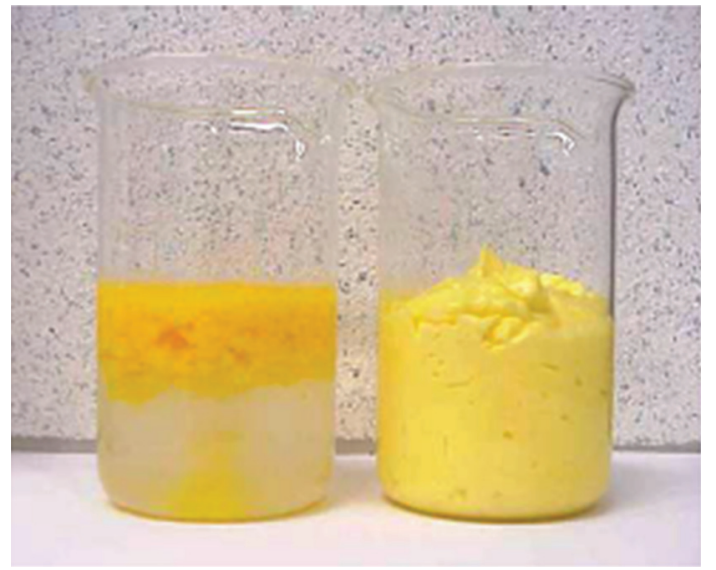

(a)

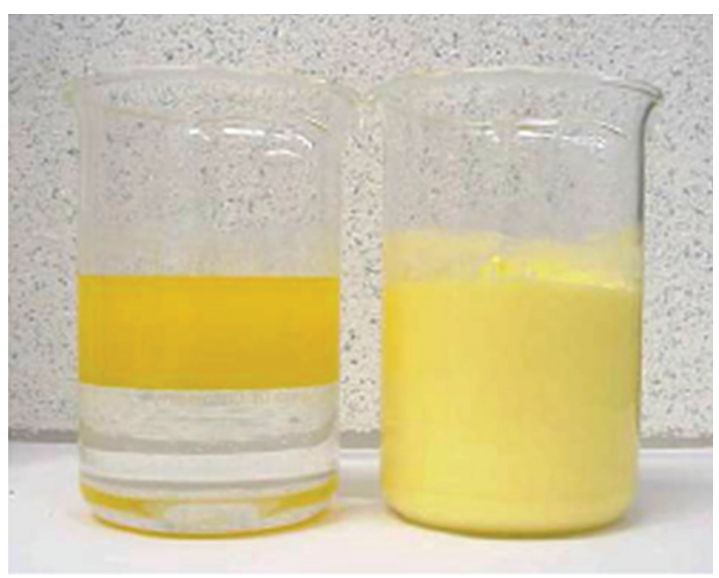

(b)

FIgURE 7: Example of a low-fat spread based on $20 \%$ fat and containing milk powder, gelatin, and sodium alginate. (a) $1 \%$ distilled monoglyceride (left) and $0.6 \%$ distilled monoglyceride $+0.4 \%$ PGPR (right). (b) $0.6 \%$ distilled monoglyceride (left) and $0.4 \%$ distilled monoglyceride + 0.2\% PGPR (right) [23]

tons of chocolate couverture. However, new requirements for biological testing led to the withdrawal of the product for this purpose, and it was not used again in chocolate production until 1958 onwards [38].

The safety testing programme on PGPR in the 1950s included acute toxicity studies in several species, 30 and $45 \mathrm{wk}$ rat feeding trials, a rat reproduction study over three generations, and a number of indirect metabolism studies to show that PGPR is digested and utilized like a normal dietary

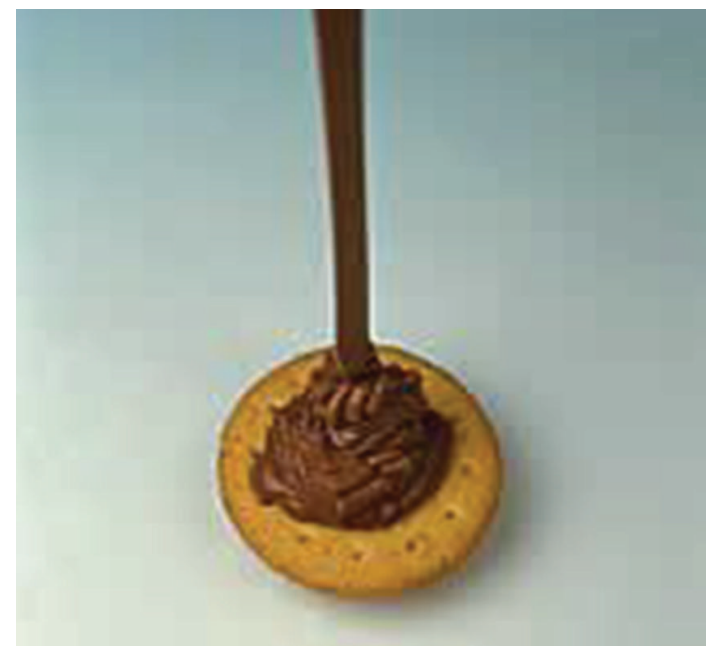

(a)

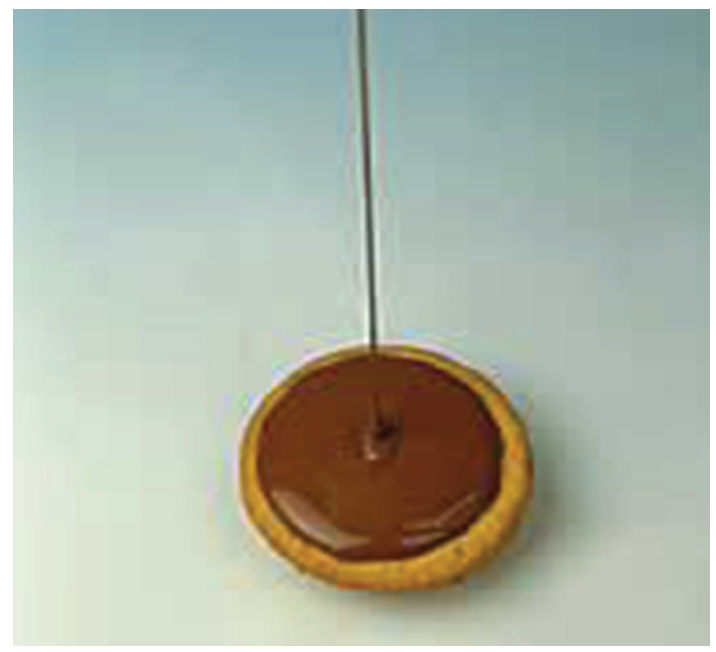

(b)

FIGURE 8: Influence of PGPR addition (0.2\%) to a molten chocolate (27\% cocoa butter) (http://www.sweetcom.de/cgi-bin/inhalt.pl?heft= 01_05\&nr=45).

fat. In the 1960s, the programme was extended to include $2 \mathrm{yr}$ rat and 80 wk mouse feeding studies, a 90 -day feeding study in a nonrodent (chicken), studies of PGPR-induced liver and kidney enlargement in rats, mice and chickens, metabolism in the rat using radiolabelled materials, and human studies on the digestibility and absorption of PGPR which included liver and kidney function tests. The results of these studies 


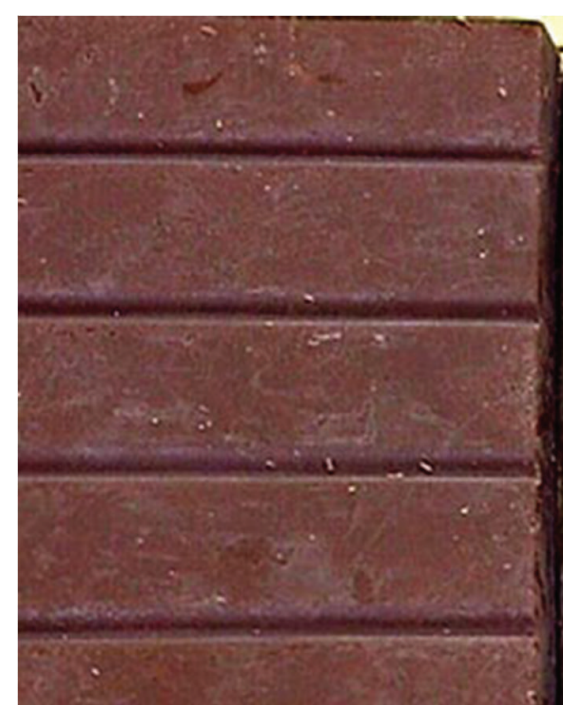

(a)

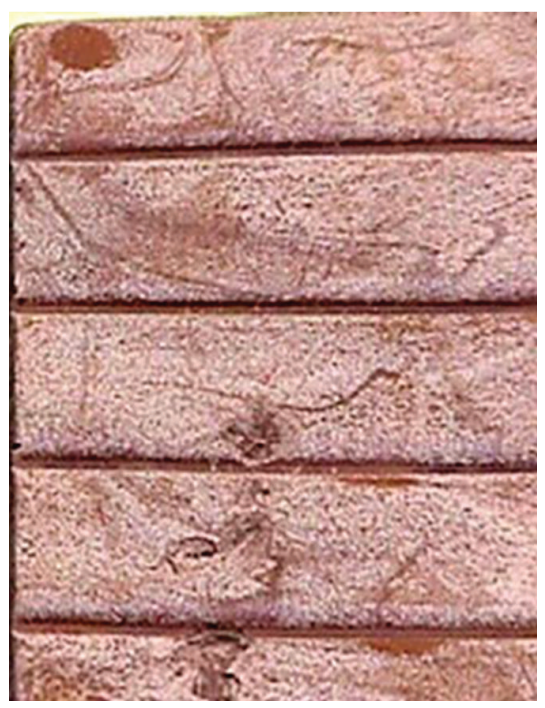

(b)

Figure 9: Effect of fat bloom in chocolate (http://www.chocolatisimo.es/fat-bloom-tu-chocolate-se-vuelve-blanquecino/).

have been published in several papers [40, 48-52]. PGPR was found to be $98 \%$ digested by rats and utilized as a source of energy superior to starch and nearly equivalent to groundnut oil. There was no interference with normal fat metabolism in rats or in the utilization of fat-soluble vitamins. Despite the intimate relationship with fat metabolism, no evidence was found of any adverse effects on such vital processes as growth, reproduction, and maintenance of tissue homeostasis. PGPR was not carcinogenic in either 2-year rat or 80 -week mouse feeding studies.

In 1969, the 13th report of the Joint FAO/WHO Expert Committee on Food Additives (JECFA) set a temporary human acceptable daily intake (ADI) for PGPR of $3.75 \mathrm{mg} / \mathrm{kg}$ body weight with a request for more biological studies. This ADI, without the temporary prefix, was raised to $7.5 \mathrm{mg} / \mathrm{kg}$ body weight in the 17th report of JECFA in 1974 [53]. In 1979, the Scientific Committee for Food (SCF) of the European Community also set an ADI for PGPR of $7.5 \mathrm{mg} / \mathrm{kg}$ body weight [54].

On the other hand, the maximum PGPR levels of use in foodstuffs ready for consumption in Europe are listed in Table 2 [55]. The European Commission established in 2008 the purity criteria for PGPR. These are listed in Table 3 [56].

\section{Production Methods of Polyglycerol Polyricinoleate}

5.1. Chemical Procedures. It is well known that chemical production of PGPR [40] is carried out in four stages:

(1) preparation of the castor oil fatty acids,

(2) condensation of the castor oil fatty acids,

(3) preparation of polyglycerol, and

(4) partial esterification of the condensed castor oil fatty acids with polyglycerol.

(1) Preparation of the Fatty Acids. The castor oil fatty acids are prepared by hydrolyzing castor oil with water and steam at elevated pressure without any added catalyst after which the resulting fatty acids are freed from glycerol by water washing. Castor oil contains, as its main fatty acid component, ricinoleic acid (80-90\%), and it is this fatty acid which is important in the condensation reaction. Other present fatty acids are oleic acid (3-8\%), linoleic acid (3-7\%), and stearic acid (0-2\%).

(2) Condensation of the Ricinoleic Acid to Produce Polyricinoleic Acid, Also Called Ricinoleic Acid Estolide. Fatty acid condensation is brought about by heating the castor oil fatty acids at elevated temperatures under vacuum and in an inert atmosphere to prevent oxidation. Samples are taken at regular intervals and tested for their free fatty acid content until an acid value of $35-40 \mathrm{mg} \mathrm{KOH} / \mathrm{g}$ is achieved. This acid value is equivalent to an average of about four-five fatty acid residues per molecule of the condensed product.

The operation conditions can be found in several papers. So, reaction temperatures between $157^{\circ} \mathrm{C}$ and $230^{\circ} \mathrm{C}[57,58]$ or between $205^{\circ} \mathrm{C}$ and $210^{\circ} \mathrm{C}$ [49] have been described. Other authors suggest not a range but a single temperature: $220^{\circ} \mathrm{C}$ [57] or $200^{\circ} \mathrm{C}$ [57]. Most researchers affirm that reduced pressure facilitates the extent of the reaction: $300-400 \mathrm{mmHg}$ [58], $45 \mathrm{mmHg}$ [57], or $20 \mathrm{mmHg}$ [49]. Either carbon dioxide $[40,59]$ or nitrogen $[51,57,58]$ can be used to ensure an inert atmosphere.

During the condensation phase, ricinoleic acid may react in a number of ways as shown in Figure 10. Simple linear esterification is the desired reaction, but cyclic esterification, which is a chain terminating process, is theoretically possible. However, no evidence was found for the presence of this type 
TABLE 2: Maximum levels of PGPR in foodstuff. European Directive 95/2/EC.

\begin{tabular}{llll}
\hline E number & Name & Foodstuff & Maximum level \\
\hline & Spreadable fats as defined in Annexes A, B, and C of Regulation (EC) & $4 \mathrm{~g} / \mathrm{kg}$ \\
& Number 2991/94 having a fat content of 41\% or less & \\
E-476 & Polyglycerol polyricinoleate & Similar spreadable products with a fat content of less than 10\% fat & $4 \mathrm{~g} / \mathrm{kg}$ \\
& & Dressings & $4 \mathrm{~g} / \mathrm{kg}$ \\
& & Cocoa-based confectionery, including chocolate & $5 \mathrm{~g} / \mathrm{kg}$ \\
\hline
\end{tabular}

TABLE 3: Purity criteria on food additives other than colours and sweeteners. European Directive 2008/84/EC.

\begin{tabular}{|c|c|}
\hline \multicolumn{2}{|c|}{ E 476 polyglycerol polyricinoleate } \\
\hline Synonyms & $\begin{array}{l}\text { Glycerol esters of condensed castor oil fatty acids } \\
\text { Polyglycerol esters of polycondensed fatty acids from castor oil } \\
\text { Polyglycerol esters of interesterified ricinoleic acid } \\
\text { PGPR }\end{array}$ \\
\hline Definition & $\begin{array}{l}\text { Polyglycerol polyricinoleate is prepared by the esterification of } \\
\text { polyglycerol with condensed castor oil fatty acids }\end{array}$ \\
\hline Description & Clear, highly viscous liquid \\
\hline \multicolumn{2}{|l|}{ Identification } \\
\hline (A) Solubility & $\begin{array}{l}\text { Insoluble in water and in ethanol } \\
\text { Soluble in ether, hydrocarbons, and halogenated hydrocarbons }\end{array}$ \\
\hline \multicolumn{2}{|c|}{$\begin{array}{l}\text { (B) Positive tests for glycerol, polyglycerol, and for } \\
\text { ricinoleic acid }\end{array}$} \\
\hline (C) Refractive index $[n]^{65}$ & Between 1.4630 and 1.4665 \\
\hline \multicolumn{2}{|l|}{ Purity } \\
\hline Polyglycerols & $\begin{array}{l}\text { The polyglycerol moiety shall be composed of not less than } 75 \% \text { of di-, tri-, and } \\
\text { tetraglycerols and shall contain not more than } 10 \% \text { of polyglycerols equal to or } \\
\text { higher than heptaglycerol }\end{array}$ \\
\hline Hydroxyl value & Not less than 80 and not more than 100 \\
\hline Acid value & Not more than 6 \\
\hline Arsenic & Not more than $3 \mathrm{mg} / \mathrm{kg}$ \\
\hline Lead & Not more than $5 \mathrm{mg} / \mathrm{kg}$ \\
\hline Mercury & Not more than $1 \mathrm{mg} / \mathrm{kg}$ \\
\hline Cadmium & Not more than $1 \mathrm{mg} / \mathrm{kg}$ \\
\hline Heavy metals (as $\mathrm{Pb})$ & Not more than $10 \mathrm{mg} / \mathrm{kg}$ \\
\hline
\end{tabular}

of cyclic material in the polyricinoleic acid. Dehydration is also possible but occurs to only a small extent.

(3) Preparation of Polyglycerol. The preparation of the polyglycerol is achieved by using one of the methods described in Section 3.

(4) Esterification of Polyricinoleic Acid with Polyglycerol. The final stage of the preparation involves heating an appropriate amount of polyglycerol with the polyricinoleic acid. The reaction takes place immediately following the preparation of the latter and in the same vessel, while the charge is still hot. The esterification conditions are the same as those for fatty acid condensation. The process is continued until a sample withdrawn from the reaction mixture is found to have a suitable acid value (acid value $\leq 6 \mathrm{mg} \mathrm{KOH} / \mathrm{g}$ in Europe) and refractive index. The major components have the general structure shown in Figure 11(a), where the average value of $n$ is about $3 . R_{1}, R_{2}$, and $R_{3}$ each may be hydrogen or a linear condensation product of ricinoleic acid with itself, as in Figure 11(b) with $\mathrm{n}$ being on average between 5 and 8 .

Some of the specifications listed in Table 3 with the exception of refractive index are weight average analysis and do not indicate specific structural characteristics of PGPR. Taken on the whole, however, these weight average-related specifications do indicate correct chemical structure, but with limited accuracy. Refractive index, however, is directly indicative of final chemical structure; for example, if the oligomer distribution of PGPR is not correct or distributed differently on the polyglycerol backbone, the refractive index measurement will not comply with the specifications as described in Table 3.

One problem with this conventional process is that the step of polymerization of ricinoleic acid is complicated by 


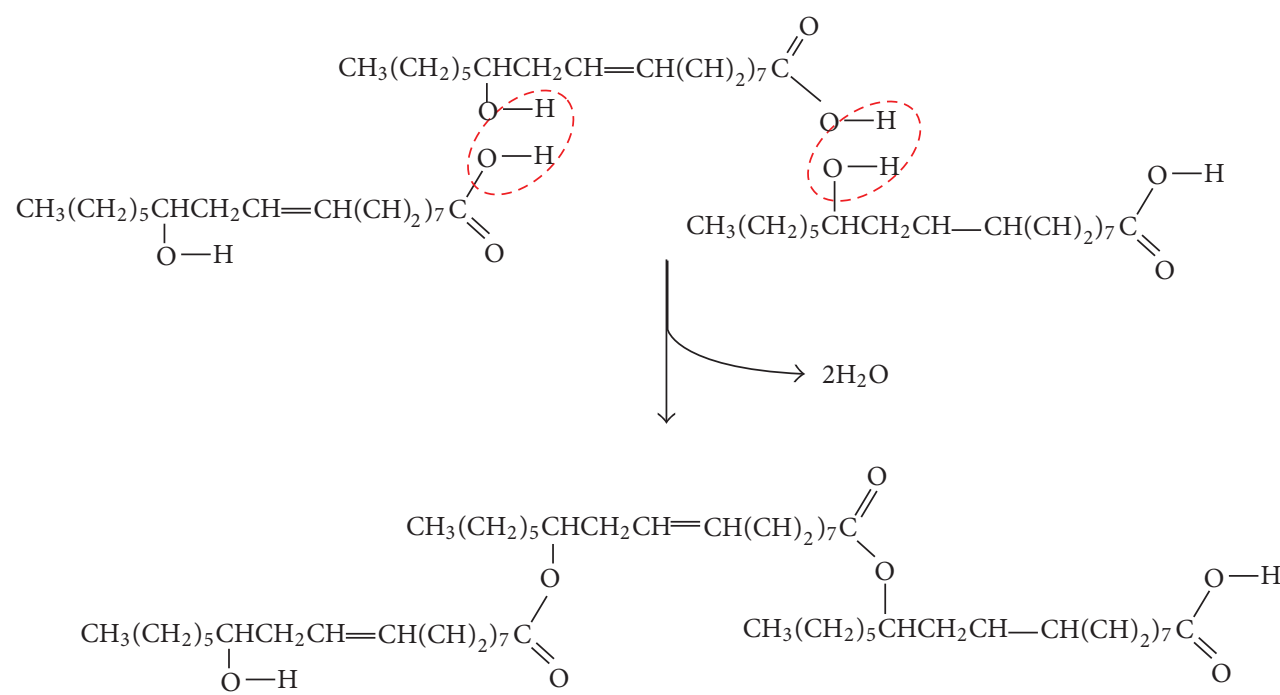

(a)

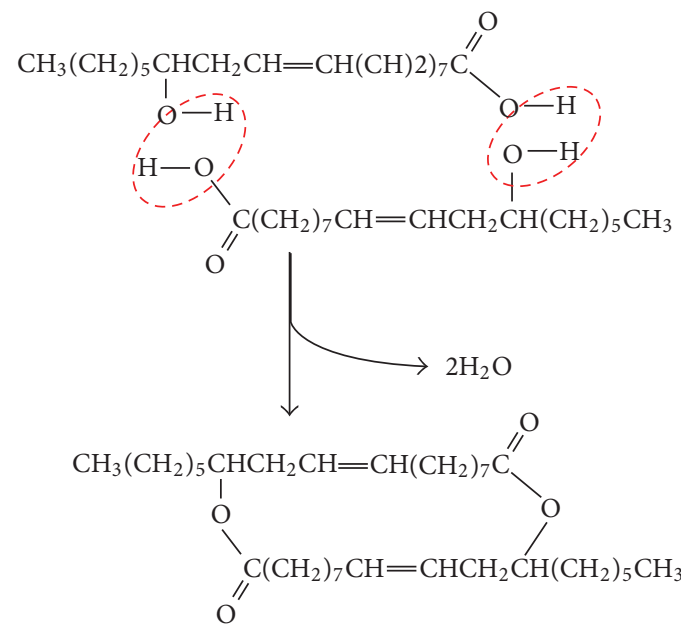

(b)

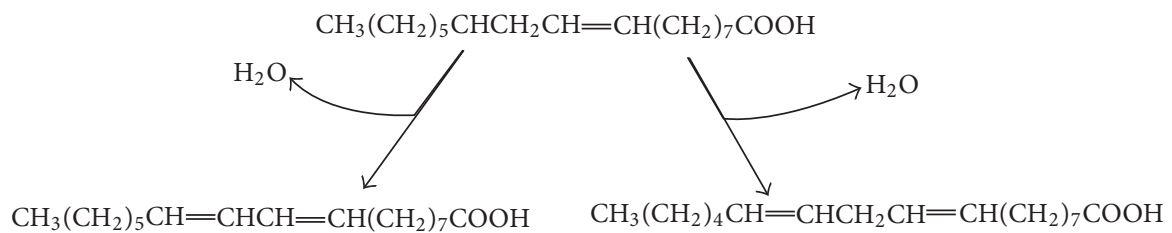

(c)

Figure 10: Possible reactions of ricinoleic acid during condensation. (a) Linear esterification, (b) cyclic esterification, and (c) dehydration (adapted from [40]).

the fact that there is a requirement to follow the refractive index (see Table 3 ) of the mixture, while polymerization of ricinoleic acid and esterificaction of polyglycerol and polyricinoleic acid is under way and to stop the reaction when the key value is indicated by the analysis. The refractive index test is not easily established in a manufacturing facility because the instrument is delicate, requires precise calibration, and requires a circulating temperature bath set to a particular temperature $\left(65^{\circ} \mathrm{C}\right)$. It is therefore difficult to run the refractive index test at the kettle, and this often requires that the instrument is used in a laboratory setting, usually in a quality control laboratory, which is both time consuming and inconvenient. Moreover, the refractive index requires a high degree of technical training and precision.

The four-step conventional process also reduces efficiency of production and adds cost to the product. Therefore, recently, a more economical and simplified chemical method for manufacturing PGPR was developed [60]. Further, in the conventional process, there is a tendency to produce compositions of darker color. This is most likely due to the added 


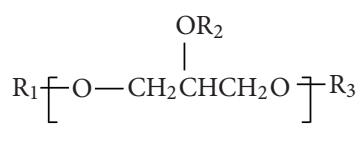

(a)

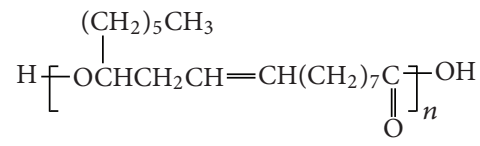

(b)

FIGURE 11: Major components of the polyglycerol polyricinoleate (adapted from [40]).

processing steps of preparing two separate ingredients, each having its own cycle of heating and cooling, along with the additional handling associated with the manufacture of each ingredient. Figure 12 shows different PGPRs with different colors.

The new process proposed in this patent produce noticeably lower color end product, such a clear yellow liquid rather than amber liquid. In this procedure [60] polyglycerol is mixed with ricinoleic, acid and they are allowed to react at $200^{\circ} \mathrm{C}$, with stirring and $\mathrm{N}_{2}$ sweep. When the acid value of the reaction mixture falls below $6 \mathrm{mg} \mathrm{KOH} / \mathrm{g}$, it was found that such a PGPR product also meets the other EC specifications, including the refractive index.

5.2. Enzymatic Synthesis. The chemical procedures above describe have the disadvantage of requiring very long reaction times, involving high energy costs. This fact, together with the high operating temperature, can adversely affect the quality of the final product because of problems related with coloration and odours, making it unsuitable for the food industry [57]. As an alternative, a biocatalytic synthesis of PGPR using enzymes has been recently proposed by the author research group [61-66]. Lipases are able to act in mild reaction conditions and produce a final product more suitable for use as a food additive.

Lipases (E.C. 3.1.1.3) are enzymes that are primarily responsible for the hydrolysis of acylglycerides. However, a number of other low- and high-molecular weight esters, thiol esters, amides, polyol/polyacid esters, and so forth are accepted as substrates by this unique group of enzymes. The wide berth for employment in a variety of reactions, endowed by this broad substrate specificity, is further enlarged by the fact that lipases are capable of catalyzing the reverse reaction of synthesis just as efficiently. In fact, some lipases are better suited for synthesis than for hydrolysis applications [67].

The two main categories in which lipase-catalyzed reactions may be classified are as follows [67].

(1) Hydrolysis:

$$
\mathrm{RCOOR}{ }^{\prime}+\mathrm{H}_{2} \mathrm{O} \longleftrightarrow \mathrm{RCOOH}+\mathrm{R}^{\prime} \mathrm{OH}
$$

(2) Synthesis: reactions under this category can be further separated as follows.

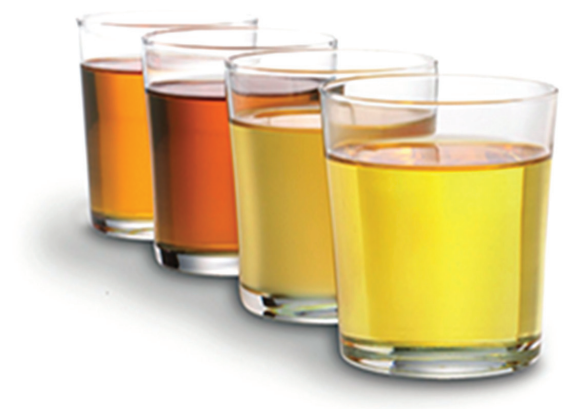

FIGURE 12: Different samples of PGPR (http://novicell.ipapercms .dk/PalsgaardAS/Brochurer/Chokolade/StandardPGPRforchocolateandcompoundsPalsgaardPGPR4120/).

(a) Esterification:

$\mathrm{RCOOH}+\mathrm{R}^{\prime} \mathrm{OH} \longleftrightarrow \mathrm{RCOOR}^{\prime}+\mathrm{H}_{2} \mathrm{O}$.

(b) Interesterification:

$\mathrm{RCOOR}^{\prime}+\mathrm{R}^{\prime \prime} \mathrm{COOR}^{*} \longleftrightarrow \mathrm{RCOOR}^{*}+\mathrm{R}^{\prime \prime} \mathrm{COOR}^{\prime}$

(c) Alcoholysis:

$\mathrm{RCOOR}^{\prime}+\mathrm{R}^{\prime \prime} \mathrm{OH} \longleftrightarrow \mathrm{RCOOR}^{\prime \prime}+\mathrm{R}^{\prime} \mathrm{OH}$.

(d) Acidolysis:

$\mathrm{RCOOR}^{\prime}+\mathrm{R}^{\prime \prime} \mathrm{COOH} \longleftrightarrow \mathrm{R}^{\prime \prime} \mathrm{COOR}^{\prime}+\mathrm{RCOOH}$.

The last three reactions are often grouped together into a single term: transesterification.

The ability of lipases to catalyze the reaction of synthesis is used in the manufacture of several products: pharmaceuticals, cosmetics, leather, detergents, foods, perfumery, medical diagnostics, and other organic synthetic materials [68]. On the other hand, lipases have been employed to catalyze reactions involving hydroxyl fatty acids (like ricinoleic acid) to narrowly shape the product distribution via their regionand stereoselectivities [69].

Esterification mixtures generally contain only the substrates and enzyme, and water is the only by-product of the reaction [67]. Many reported lipase-catalyzed syntheses are carried out in organic solvents. However, residues of organic solvents in products are undesired, and many solvents which could be used are even toxic and are not allowed for processing procedures to make products for food applications. As well as that, removal of organic-solvent traces in products requires extra expense and increases manufacturing costs. Solvent-free processes are thus desired [70-73] due to their advantages [72] and because they fulfill the twelve principles of the Green Chemistry, as defined by Anastas and Warner [74].

The potential of this relatively easy to perform bioconversion for industrial purposes seems to be enormous, but there are only few examples of successful production processes in 
practice. There are some important reasons for this. The use of dried enzyme powders, although often reported in laboratory scale experiments, is generally unsuitable for large scale processing in nonaqueous media. Development of the enzymes into active and stable biocatalysts, usually by appropriate immobilization techniques on support materials suitable for large scale production processes on a multitons basis, is very important. At the moment there are only a few off-the-shelf purpose made biocatalysts commercially available which are suitable for industrial production [73].

Taking into account all these considerations, we developed a novel method for PGPR production, using immobilized lipase and in a solvent-free system [61-66]. This process is environmentally friendly and avoids side reaction, so that the product has a higher purity and quality. The enzymatic procedure consists of two steps (similar to chemical procedure). First, the ricinoleic acid is polymerized to obtain the polyricinoleic acid, $\mathrm{PR}$, also known as ricinoleic acid estolide [62-64]. Then, it is esterified with polyglycerol to obtain polyglycerol polyricinoleate, $\operatorname{PGPR}[61,65,66]$. Figure 13 shows the reactions involved in the biosynthesis.

5.2.1. Polymerization of Ricinoleic Acid. The studies about the first reaction step are based on previous works $[69,75-$ 80] and a result of this conscientious bibliographical search; Candida rugosa lipase has been selected to catalyze the autocondensation reaction of ricinoleic acid to obtain the polyricinoleic acid.

Immobilization of Candida rugosa Lipase. First of all, efforts have been devoted to obtaining an immobilized derivative with a high immobilized protein percentage and enzymatic activity for the present application [63].

It has been described that adsorbed lipase on a ceramic carrier SM-10 [79] is suitable for producing ricinoleic acid estolide. However, the difficulty of acquiring the support led the authors to test different immobilization matrices in an attempt to obtain an immobilized derivative, which could be successfully used to catalyze the production of ricinoleic acid estolide [63]. Eight inorganic supports (two types of BioLite, Celite R-643, Chromosorb W, nonporous glass beads of two particle sizes, and porous glass beads of different pore sizes) and two organic carriers (cationic and anionic exchange resins, Dowex $50 \times 8$ and Lewatit MonoPlus MP 64, resp.) have been used. Twelve different immobilized derivatives have been obtained, six of them by physical adsorption and the other six by covalent coupling via the amino groups of the enzyme. Immobilization on glutaraldehyde-activated aminopropyl glass beads was selected because it has been widely used by the authors with different enzymes [81, 82] and has been shown to be very versatile.

The results obtained are shown in Table 4 where percentages of immobilized protein and protein contents are summarized. It is important to note that these values are based on the protein content provided by Lowry's method [83], which showed that the commercial lipase contained only $15 \%$ protein.
The best results have been obtained when porous glass was used as immobilization matrix and covalent binding as coupling method. In these cases enzyme loading increased, as the pore size became smaller because of the greater internal surface available for immobilization. The percentage of immobilized lipase obtained by physical adsorption on Lewatit MonoPlus MP 64 was higher than those obtained with porous glass because five times less enzyme was offered for immobilization, so that enzyme loading ( $\mathrm{mg} \mathrm{E} / \mathrm{g}$ support) was noticeably lower. Celite R-643 was also shown to be suitable for Candida rugosa lipase immobilization.

The five above mentioned immobilized derivatives were used to catalyze the polymerization reaction of ricinoleic acid. The extent of the reaction was monitored by acid value measures [84]. Figure 14 shows the results obtained.

It can be seen that there was a large difference between the activity of the derivative obtained on the anion exchange resin and the activity of other derivatives. In the case of the anion exchange resin, the acid value dropped from 180 to 50 in $150 \mathrm{~h}$, while the best result of the other derivatives was a fall to 136 in $285 \mathrm{~h}$ (porous glass 75-400). Therefore, the immobilized lipase obtained by physical adsorption onto Lewatit MonoPlus MP 64 was chosen for PR production. Moreover, other studies showed that the activation of the support with soybean lecithin has a beneficial effect on the enzymatic activity and that the optimum $\mathrm{pH}$ for enzyme immobilization is 7 [63].

Optimization of the Reaction Conditions. The optimization of some reaction conditions is especially important in an experimental system like the described one. It is known that temperature is a crucial parameter in every enzyme catalyzed reactor, but in this case, due to the special characteristics of the reaction medium (solvent free), temperature greatly influences viscosity, mass transport phenomena, and, as a consequence, the esterification rate [85]. While high temperature favors the medium fluidity, enzyme has to be prevented from thermal deactivation [62-64, 85, 86]. The optimum temperature for polyricinoleic acid synthesis catalyzed with immobilized Candida rugosa lipase was $40^{\circ} \mathrm{C}$. Lower reaction rates have been detected below this value, and a slightly unfavourable effect could be observed at high temperature [63].

Another decisive parameter in this process is the water content. Water plays multiple roles in lipase-catalyzed esterifications performed in nonconventional media. It is widely known that water is absolutely necessary for the catalytic function of enzymes because it participates, directly or indirectly, in all noncovalent interactions that maintain the conformation of the catalytic site of enzymes [62-64, 8789]. However, it has been found that the amount of water necessary for enzyme activity might be very small, and, in the case of lipase, just a few layers around the enzyme surface are needed [90]. On the other hand, in esterification/hydrolysis reactions it is well known that the water content affects the equilibrium conversion of the reactions. Particularly, in the case of estolides production, the water formed by the reaction must be removed from the reaction mixture if polyricinoleic 

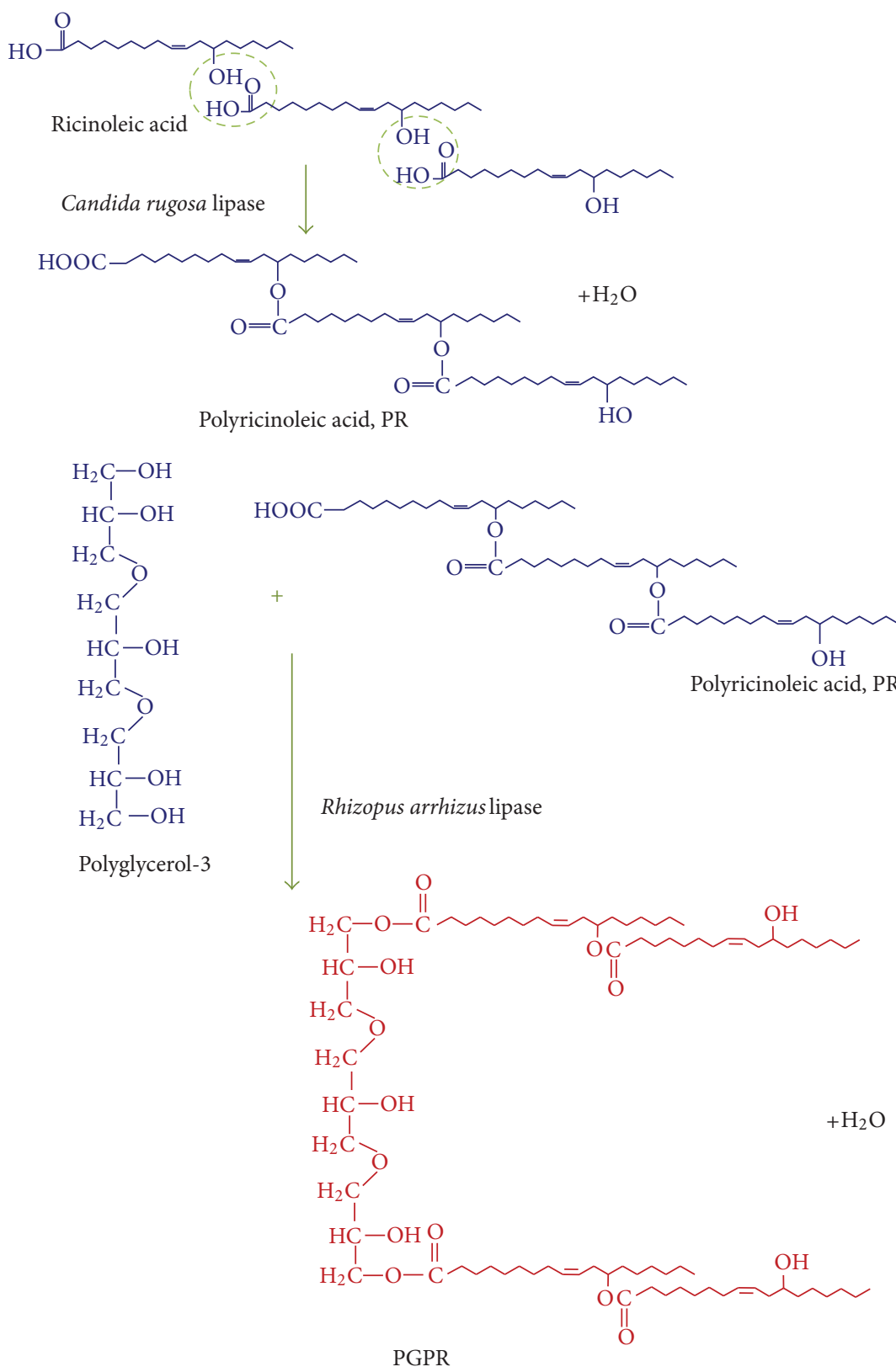

FIgURE 13: Biocatalytic synthesis of PGPR. First reaction catalyzed by Candida rugosa lipase and second reaction catalyzed by Rhizopus arrhizus lipase.

acid with a high degree of condensation is to be obtained [62$64,79]$. In the light of the above considerations, a study on the optimal initial amount of water in the reactor was deemed necessary. With this purpose, the authors carried out four experiments using the immobilized derivative as obtained (soaked), adding different amounts of water and drying the derivative under vacuum at room temperature before use [64]. The time course of these experiments is shown in Figure 15 where the acid value is represented against operation time.

With these experiments it was demonstrated that an optimum in the initial water content exists, although this optimum seems to be quite wide. The same results were obtained when derivative was used as obtained and when small amounts of water were added. However, drying the derivative or adding higher amounts of water led to a lower initial rate (specially the high water content) and a higher final acid value [64].

Production of PR in a Vacuum Reactor. All the experiments described above were carried out simultaneously, in an air open tank reactor, within a month of each other. However, when the results were tested for reproducibility, great discrepancy between them was observed, where a variation of $30 \%$ 


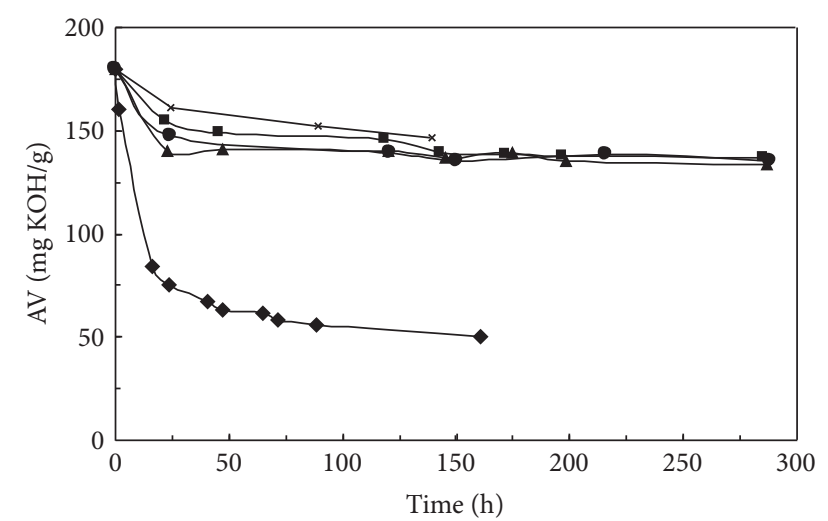

FIGURE 14: Change in acid value as a function of time for estolide synthesis catalysed by five different immobilized derivatives [63]. (\$) Celite R-643, (ロ) PG 75-400, and (×) PG 700-400, (•) PG 1000-400, (\) Lewatit MonoPlus MP 64.

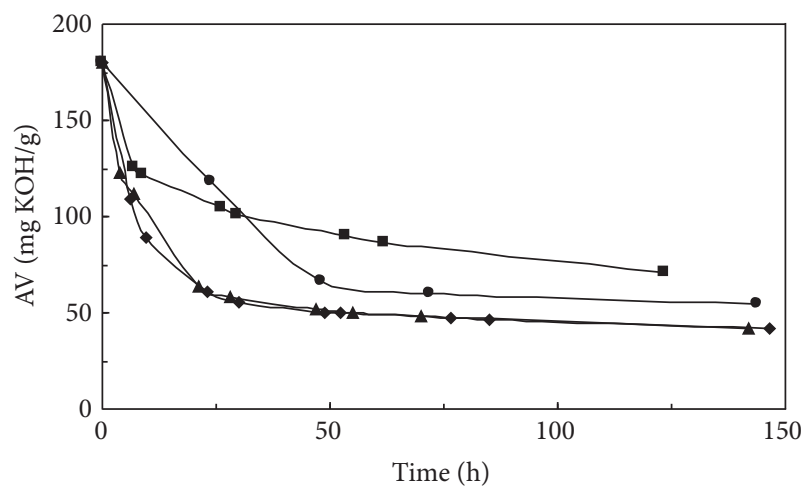

FIGURE 15: Influence of the initial water content on the evolution of acid value with time for the PR synthesis in the open reactor [64]. ( $\mathbf{\Delta})$ wet resin, $(\bullet)$ dry resin, $(\square)$ addition of $0.1 \mathrm{~mL}$ water/g immobilized derivative, and ( ) addition of $1 \mathrm{~mL}$ water/g immobilized derivative.

in the AV value was obtained for experiments carried out in different seasons. Measurements of the water content of the reaction medium revealed that, at $40^{\circ} \mathrm{C}$, water continuously evaporated and that after $48 \mathrm{~h}$ (approximately) the reactor water content was independent of the initial water content and mainly dependent on environmental relative humidity. The air conditioner/heat pump equipment installed in the laboratory stabilizes the relative humidity at $70 \%$ in summer (air conditioner) and at $20 \%$ in winter (heat pump). These values correspond with equilibrium water contents of 3600 and $1000 \mathrm{ppm}$, respectively, which are the cause of the discrepancies in the results obtained in the open-air reactor. Obviously, this poor reproducibility of the results is unacceptable if the process is to be applied on an industrial scale [64].

For this reason, the production of PR should be carried out in a closed system with controlled atmosphere, a suitable level of stirring and low pressure. Moreover, to enhance dehydration, a current of dry nitrogen was passed through the reaction mixture for a period of 7 hours, and after that, maintenance of the vacuum $(160 \mathrm{~mm} \mathrm{Hg})$. In these conditions, the water content in the reactor can be adequately controlled (3000 ppm), and an estolide with a high degree of polymerisation $(\mathrm{AV} \approx 40 \mathrm{mg} \mathrm{KOH} / \mathrm{g})$ can be obtained [64].

\subsubsection{Esterification of Polyricinoleic Acid with Polyglycerol.} Once we are able to produce polyricinoleic acid with the appropriate acid value, it is used as substrate of the second reaction, that is, the esterification of PR with polyglycerol.

Selection of Lipases. Lipase from Candida rugosa was used to carry out the autocondensation of ricinoleic acid to obtain the estolide, which is the first step in PGPR synthesis. Obviously, it would be very convenient if the same lipase could serve as catalyst for the two reaction steps. However, several studies revealed that Candida rugosa lipase was unsuitable for PGPR synthesis, and therefore others lipases were assayed for this purpose [65].

A further twenty lipases from different sources were used, and the corresponding experiments of PGPR synthesis were performed. Table 5 shows the lipases tested, their specific activities (as declared by the manufacturer), and the amounts of protein used in each experiment. It is important to note that many of the lipases were part of two kits [91] and the amount available was limited. In such cases, the total available protein was added to the reactor.

The evolution of the acid value with time for the enzymatic production of PGPR with the above mentioned lipases is plotted in Figures from 16(a) to 16(d). In a first selection, eight lipases were rejected because they were not able to reach acid values lower than $15 \mathrm{mg} \mathrm{KOH} / \mathrm{g}$ in seven days; they are lipases from Aspergillus sp., Candida antarctica, Candida cylindracea, Candida lipolytica, Penicillium roqueforti, porcine pancreas, Rhizopus niveus, and wheat germ [65].

The lipase from wheat germ exhibited a particular behavior. When it was tested to produce PGPR, the acid value of the reaction mixture increased, which indicates that polyricinoleic acid is being hydrolyzed, and therefore, under the experimental conditions, the hydrolytic activity of this lipase is greater than its synthetic activity. None of the twelve remaining lipases were able to produce a PGPR with an acid value lower that $6 \mathrm{mg} \mathrm{KOH} / \mathrm{g}$, which is the requirement of the European Commission Directive [56], although we considered that, after applying appropriate optimization procedures, one or more of these enzymes might be able to efficiently catalyze the enzymatic synthesis of PGPR [65].

The twelve chosen lipases were all from microbial sources, being some 1,3 specific and others "random" lipases. It was thought that any acid value decay in the reaction mixture might be due to two possible reactions: (i) the synthesis of estolides with a higher polymerization degree and (ii) the esterification of polyricinoleic acid with polyglycerol-3 (the desired process). It has been described in the literature that the enzymatic synthesis of estolides can only be successfully catalyzed by lipases that lack 1,3 positional selectivity [68, $69,92]$, so that lipases from Chromobacterium viscosum and from Pseudomonas (which are "random" lipases and show the best results, Figure 16(d)) should be capable, in theory at least, of catalyzing the first step of the enzymatic synthesis 
TABLE 4: Coupling parameters for the immobilization of Candida rugosa lipase in different supports [63].

\begin{tabular}{lccc}
\hline Support & Immobilization method & Immobilized protein (\%) & Enzyme loading (mg E/g support) \\
\hline Biolita L2.7 & $\begin{array}{c}\text { Adsorption } \\
\text { Covalent binding }\end{array}$ & - & - \\
\hline Biolita P3.5 & Adsorption & 0.64 & - \\
Celite R-643 & & 27.60 & 4.14 \\
Chromosorb W & & - & - \\
\hline Nonporous glass $425-600 \mu \mathrm{m}$ & Covalent binding & 0.89 & - \\
Nonporous glass 91-107 $\mu \mathrm{m}$ & & 41.73 & 31.30 \\
PG 75-400 & & 28.65 & 21.49 \\
PG 700-400 & & 22.83 & 17.12 \\
PG 1000-400 & & - & - \\
Cationic exchange resin Dowex $50 \times 8$ & Adsorption & 47.20 & 7.08 \\
Anionic exchange resin & & & \\
Lewatit MonoPlus & & & \\
MP 64 & & & \\
\hline
\end{tabular}

TABLE 5: Lipases tested to catalyze the enzymatic production of PGPR [64].

\begin{tabular}{|c|c|c|c|c|}
\hline & Enzyme & Source & $\begin{array}{c}\text { Activity (U/mg solid) } \\
\text { (as declared by the manufacturer) }\end{array}$ & Added amount (mg) \\
\hline \multirow{9}{*}{$\frac{\text { : }}{4}$} & 1 & Aspergillus sp. & $0.20^{(1)}$ & 100 \\
\hline & 2 & Candida antarctica & $2.9^{(2)}$ & 50 \\
\hline & 3 & Candida cylindracea & $3.85^{(2)}$ & 1000 \\
\hline & 4 & Mucor miehei & $1.4^{(2)}$ & 100 \\
\hline & 5 & Pseudomonas cepacia & $46.2^{(2)}$ & 100 \\
\hline & 6 & Pseudomonas fluorescens & $36^{(2)}$ & 50 \\
\hline & 7 & Rhizopus arrhizus & $9.18^{(3)}$ & 500 \\
\hline & 8 & Rhizopus niveus & $1.7^{(4)}$ & 1000 \\
\hline & 9 & Porcine pancreas & $20.6^{(5)}$ & 1000 \\
\hline \multirow{11}{*}{ 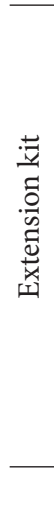 } & 10 & Aspergillus oryzae & $48^{(2)}$ & 100 \\
\hline & 11 & Candida lipolytica & $0.0011^{(2)}$ & 1000 \\
\hline & 12 & Mucor javanicus & $11.6^{(5)}$ & 500 \\
\hline & 13 & Penicillium roqueforti & $0.65^{(5)}$ & 500 \\
\hline & 14 & Pseudomonas fluorescens & $309^{(2)}$ & 50 \\
\hline & 15 & Rhizomucor miehei recombinant from Aspergillus oryzae & $0.51^{(2)}$ & 50 \\
\hline & 16 & Wheat germ & $0.1^{(1)}$ & 500 \\
\hline & 17 & Chromobacterium viscosum & $2711^{(2)}$ & 25 \\
\hline & 18 & Pseudomonas sp. & $2324^{(2)}$ & 10 \\
\hline & 19 & Pseudomonas sp. (Type B) & $256^{(6)}$ & 50 \\
\hline & 20 & Rhizopus oryzae & $58.4^{(7)}$ & 500 \\
\hline
\end{tabular}

\footnotetext{
(1) 1 unit corresponds to the amount of enzyme which liberates $1 \mu \mathrm{mol}$ acetic acid per minute at $\mathrm{pH} 7.4$ and $40^{\circ} \mathrm{C}$, using triacetin as substrate.

(2) 1 unit corresponds to the amount of enzyme which liberates $1 \mu \mathrm{mol}$ oleic acid per minute at $\mathrm{pH} 8.0$ and $40^{\circ} \mathrm{C}$, using triolein as substrate.

${ }^{(3)} 1$ unit corresponds to the amount of enzyme which liberates $1 \mu \mathrm{mol}$ butyric acid per minute at $\mathrm{pH} 8.0$ and $40^{\circ} \mathrm{C}$, using tributyrin as substrate.

(4) 1 unit corresponds to the amount of enzyme which liberates $1 \mu \mathrm{mol}$ fatty acid from a triglyceride per minute at $\mathrm{pH} 7.7$ and $37^{\circ} \mathrm{C}$, using olive oil as substrate.

${ }^{(5)} \mathrm{As}^{(4)}$ but at $\mathrm{pH}$ 8.0.

${ }^{(6)} 1$ unit corresponds to the amount of enzyme which liberates $1 \mu \mathrm{mol}$ oleic acid per minute at $\mathrm{pH} 8.0$ and $37^{\circ} \mathrm{C}$, using cholesteryl oleat as substrate.

${ }^{(7)} \mathrm{As}^{(4)}$ but at $\mathrm{pH} 7.2$.
} 


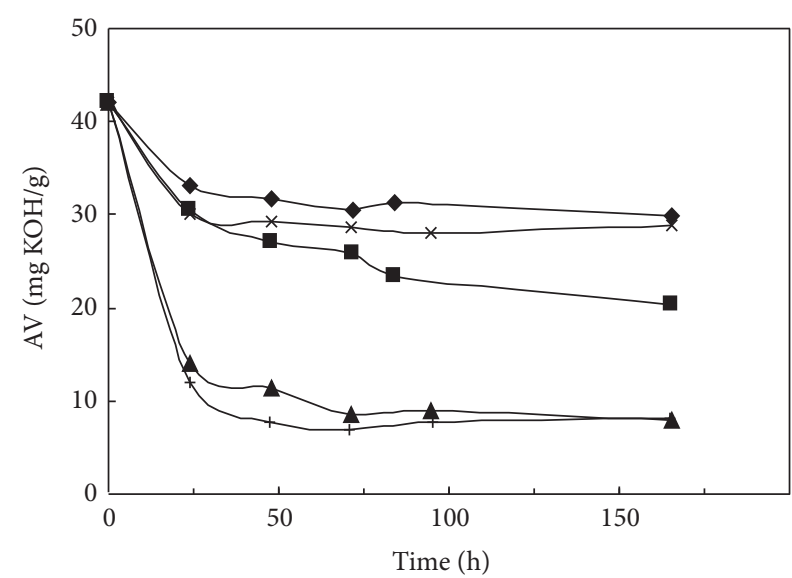

(a)

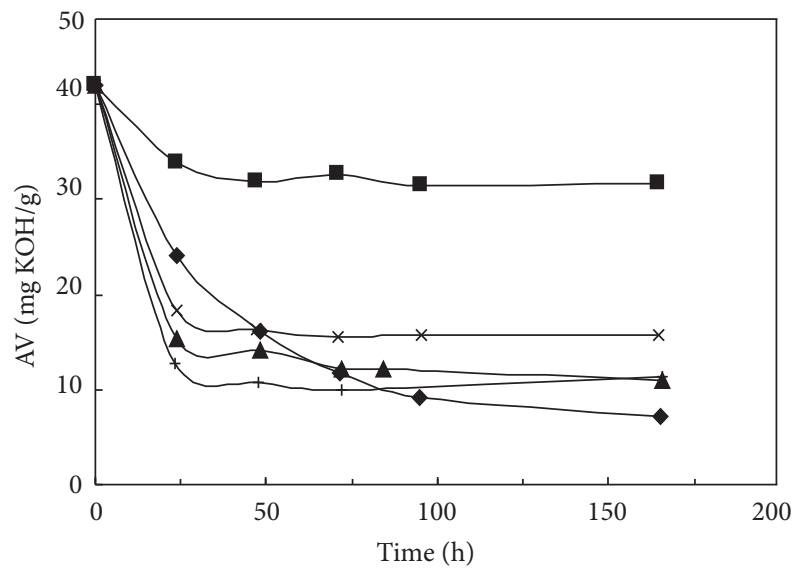

(c)

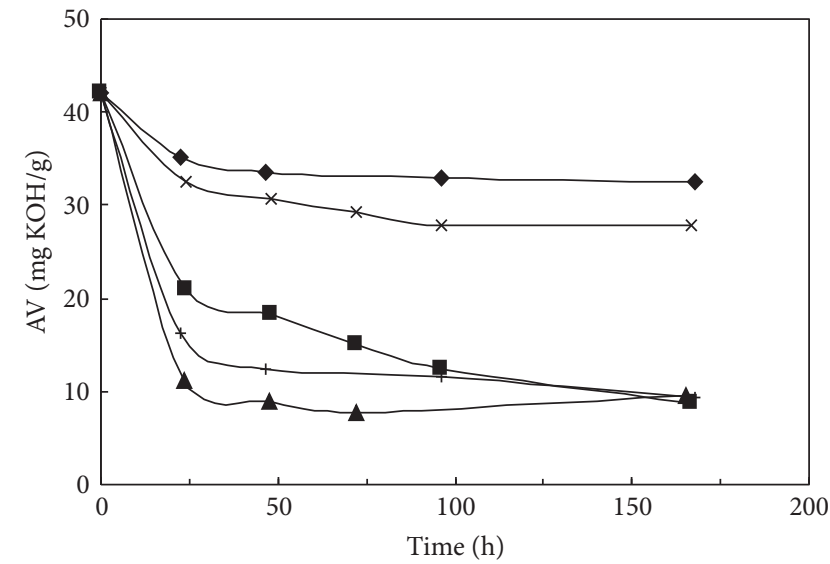

(b)

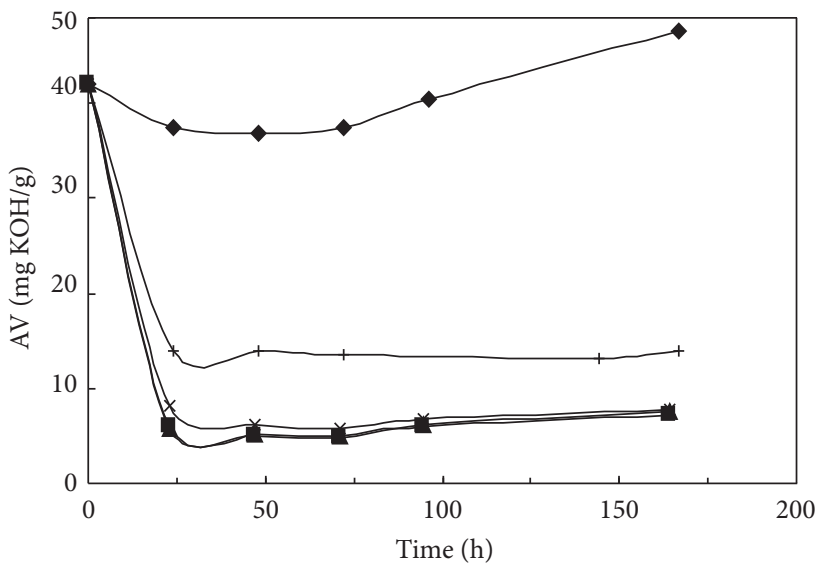

(d)

FIgure 16: Evolution of acid value with time for the PGPR synthesis catalysed by free lipases from different sources [65]. (a) Aspergillus sp.; Candida antarctica; $\times$ Candida cylindracea; $\Delta$ Mucor miehei; + Pseudomonas cepacia. (b) Candida lipolytica; Mucor javanicus; $\times$ Penicillium roquefortii; $\Delta$ Pseudomonas fluorescens $(300 \mathrm{U} / \mathrm{mg}$ solid); + Rhizomucor miehei. (c) $\downarrow$ Pseudomonas fluorescens (40 U/mg solid); $\square$ Porcine pancreas; $\times$ Rhizopus niveus; $\triangle$ Rhizopus arrhizus; + Aspergillus oryzae. (d) Wheat germ; $\mathbf{\square}$ Chromobacterium viscosum; $\times$ Pseudomonas sp. (1200 U/mg solid); ^ Pseudomonas sp. Type B ( $\geq 60 \mathrm{U} / \mathrm{mg}$ solid); + Rhizopus oryzae.

of PGPR. However, it was experimentally demonstrated that, under the assayed experimental conditions, these lipases are not capable of catalyzing the production of estolides with an acid value lower than $50 \mathrm{mg} \mathrm{KOH} / \mathrm{g}$ (data not shown), so that the noticeable decrease of the acid value observed in the above described experiments can be attributed mainly to the esterification reaction between polyricinoleic acid and polyglycerol. In case of the reactions catalyzed by the remaining lipases tested, there is no doubt about the cause of the decrease of acid value, because they are 1,3-specific and cannot act on hydroxy fatty acids [69].

On the other hand, it may be surprise that Mucor javanicus and Rhizopus sp. lipases (1, 3 specific) performed so well. If polyglycerol-3 is a linear molecule, only two of the five hydroxyl groups available as acyl acceptor groups are primary, and the acid value reached when these lipases are used indicates that more than two hydroxyl groups have been esterified. This fact can be explained if condensation of glycerol takes place between secondary-primary or secondary-secondary hydroxyl groups. In that case more than two primary hydroxyl groups may remain available as acyl acceptor groups.

As can be seen in Figure 16, satisfactory results were obtained when the twelve mentioned lipases were used to catalyze the production of PGPR, and some graphs are indistinguishable. Table 6 shows the acid values reached after 7 days of reaction, which permits a better comparison of the obtained results. It can be observed that the lowest acid values were reached when lipases from Pseudomonas (3 enzymes) and Chromobacterium viscosum were used. However, some of the lipases used in the present work are very expensive, which is an aspect that should be carefully considered if the longterm purpose is to develop an industrial procedure for PGPR production. Therefore, in order to finally choose one or more of these lipases, we took into account not only kinetic aspects (reaction rates and final acid value of the reaction mixture) but also the cost of the procedure. 
TABLE 6: Selection of lipases based on kinetic and economic aspects [65].

\begin{tabular}{|c|c|c|c|c|c|}
\hline Enzyme $^{(1)}$ & Source & Final AV (mg KOH/g) after 7 days & $\Delta \mathrm{AV}^{(2)}$ & Enzyme cost ${ }^{(3)}(€)$ & $€ /$ unit $\mathrm{AV}^{(4)}$ \\
\hline 4 & Mucor miehei & 8.0 & 34.0 & 46.8 & 1.4 \\
\hline 5 & Pseudomonas cepacia & 8.1 & 33.9 & 35.7 & 1.1 \\
\hline 6 & P. fluorescens (36 U/mg solid) & 7.2 & 34.8 & 35.3 & 1.0 \\
\hline 7 & Rhizopus arrhizus & 11.0 & 31.0 & 22.9 & 0.7 \\
\hline 10 & Aspergillus oryzae & 11.4 & 30.6 & 85.2 & 2.8 \\
\hline 12 & Mucor javanicus & 8.7 & 33.3 & 22.0 & 0.7 \\
\hline 14 & P. fluorescens (309 U/mg solid) & 9.6 & 32.4 & 110.5 & 3.4 \\
\hline 15 & Rhizomucor miehei & 9.3 & 32.7 & 27.4 & 0.8 \\
\hline 17 & Chromobacterium viscosum & 7.1 & 34.9 & 43.4 & 1.2 \\
\hline 18 & Pseudomonas sp. (2324 U/mg solid) & 7.7 & 34.3 & 44.6 & 1.3 \\
\hline 19 & Pseudomonas sp. Type B (256 U/mg solid) & 7.6 & 34.4 & 43.0 & 1.2 \\
\hline 20 & Rhizopus oryzae & 13.9 & 28.1 & 1.8 & 0.06 \\
\hline
\end{tabular}

${ }^{(1)}$ Enzyme identification numbers are the same that those used in Table 5.

${ }^{(2)}$ Calculated as the difference between initial AV (42.0 mg KOH/g) and final AV (3rd column).

${ }^{(3)}$ Estimated from commercial price lists.

${ }^{(4)}$ Calculated as column 5 and divided by column 4 .

TABLE 7: Coupling parameters for the immobilization of lipases onto Lewatit MonoPlus MP 64 [65].

\begin{tabular}{lccc}
\hline Lipase source & Protein content of the commercial lipase (\%) & Immobilisation yield (\%) & Enzyme loading (mg E/g support) \\
\hline Mucor javanicus & 22.07 & 63.90 & 14.11 \\
Rhizopus arrhizus & 26.35 & 32.59 & 8.59 \\
Rhizopus oryzae & 19.80 & 65.03 & 12.88 \\
\hline
\end{tabular}

In order to evaluate this economic aspect of the enzymatic biosynthesis of PGPR and because lipase is the most expensive material involved in the reaction, the cost of biocatalysts that cause a decrease of one unit of the acid value was calculated, and the results are showed in the last column of Table 6. It can be observed that the cheapest procedures were those catalyzed by lipases from the fungi Rhizopus oryzae, Rhizopus arrhizus, Mucor javanicus, Rhizomucor miehei, and Rhizopus niveus, with which the decrease of one unit in acid value costs less than $1 €$. These results, together with those shown in Figure 16, led us to select lipases from Rhizopus oryzae, Rhizopus arrhizus, and Mucor javanicus to catalyze PGPR synthesis [65].

Although the above selected lipases are not very expensive to develop an industrial procedure for PGPR synthesis, it is desirable to use immobilized enzymes because of its well-known advantages: continuous operation of reactors and/or the reusability of the immobilized enzymes, both of which diminish operational costs. Therefore, the three chosen lipases were immobilized by physical adsorption onto an anion exchange resin (Lewatit MonoPlus MP 64). As described previously, the authors have optimized the immobilization process of Candida rugosa lipase, and as a preliminary attempt the same technique was used in this work in order to compare the behavior of these three lipases. In further studies the immobilization process should be optimized.

Thus, three immobilized derivatives were prepared, and the results are shown in Table 7 , where the protein content of the commercial lipases, the immobilization yields, and the enzyme loadings of all the immobilized derivatives are summarized, all data being based on the protein concentration values provided by Lowry's method [83]. It should be mentioned here that the protein content of the three commercial preparations was quite low, although that of the lipase from Rhizopus arrhizus was slightly higher than the others. However, the percentage of immobilized protein obtained with this lipase was approximately half that obtained with the other two lipases, and so the enzyme loading factor of this immobilized derivative was the lowest $(8.59 \mathrm{mg} \mathrm{E} / \mathrm{g}$ support). The highest immobilization yield was achieved when the lipase from Rhizopus oryzae was adsorbed; in this case an immobilized derivative with adequate enzyme content was obtained despite of the low Lowry protein content of the commercial enzyme. The immobilized derivative of lipase from Mucor javanicus had the higher enzyme loading, $14.11 \mathrm{mg}$ E/g support.

The above results did not differ sufficiently to permit us to decide at this stage which of the three lipases should be selected. Therefore the immobilized derivatives were tested for activity, using them to catalyze the synthesis of PGPR. Figure 17 shows the variation of the acid value of the reaction mixtures with time. As can be seen, all the immobilized derivatives showed their ability to catalyze the esterification between polyricinoleic acid and polyglycerol. The use of the lipase from Mucor javanicus should not be totally discarded because reasonably good results were obtained when it was 


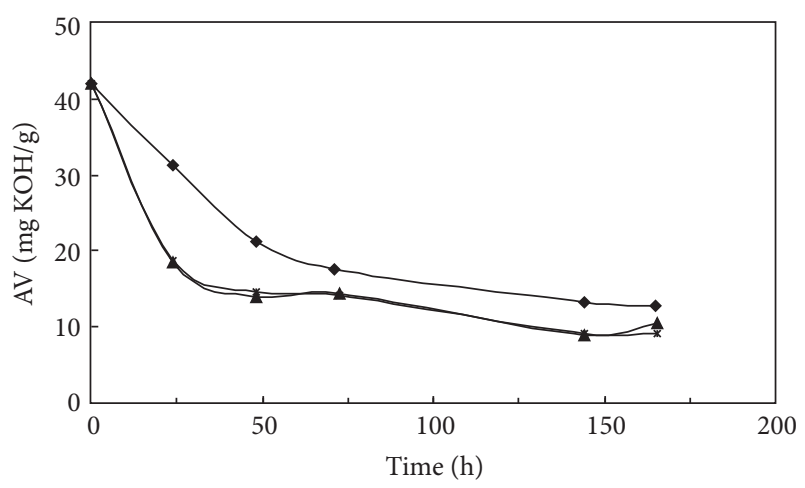

FIGURE 17: Evolution of acid value with time for the PGPR synthesis catalysed by immobilized lipases from different sources [65]. (\$) Mucor javanicus, (\) Rhizopus arrhizus, and (×) Rhizopus oryzae.

used as biocatalyst, and a PGPR with an acid value of $13 \mathrm{mg} \mathrm{KOH} / \mathrm{g}$ was reached at the end of the experiment.

The highest reaction rates were achieved when lipases from Rhizopus arrhizus and Rhizopus oryzae were used, and in these cases, PGPRs with lower acid values were produced. Comparing these results with those obtained with the soluble enzymes, it can be observed that the acid values reached with the immobilized derivatives $(10.42 \mathrm{mg} \mathrm{KOH} / \mathrm{g}$ with lipase from Rhizopus arrhizus and $9.22 \mathrm{mg} \mathrm{KOH} / \mathrm{g}$ with lipase from Rhizopus oryzae) were similar to those obtained with the soluble lipases $(11.04 \mathrm{mg} \mathrm{KOH} / \mathrm{g}$ and $13.94 \mathrm{mg} \mathrm{KOH} / \mathrm{g}$, respectively, Table 6), even though the amounts of soluble enzymes added to the reactors (500 $\mathrm{mg}$ in both cases) were higher than those used in the experiments with immobilized enzymes ( $42.95 \mathrm{mg}$ lipase from Rhizopus arrhizus and $64.4 \mathrm{mg}$ lipase from Rhizopus oryzae). These results suggest that immobilisation had a beneficial effect on the activity and stability of both lipases [65].

Lipase from Rhizopus arrhizus was selected for PGPR production because lower amount of enzyme is required to achieve the same final acid value [66].

Optimization of the Reaction Conditions. After a detailed literature search, no references were found, which might indicate, even approximately, the experimental conditions in which the reaction should be carried out. Therefore, it was necessary to start the study of the enzymatic synthesis of PGPR by establishing the optimal experimental conditions [66].

The polyricinoleic acid (PR), used as substrate, has an acid number lower than $50 \mathrm{mg} \mathrm{KOH} / \mathrm{g}$. At this acid number value, the average length of the PR chains is four, which is considered as optimum for food use by most authors $[62,79]$. Among the commercially available polyglycerols, polyglycerol-3 from Solvay (PR-3) was considered the most appropriate because it produces a high performance PGPR [23]. As described previously, the European Commission Directive 2008/84/EC [56] establishes an acid value (AV) lower than $6 \mathrm{mg} \mathrm{KOH} / \mathrm{g}$ for PGPR and a hydroxyl value (HV) of between 80 and $100 \mathrm{mg} \mathrm{KOH} / \mathrm{g}$. HV is a measurement of the free hydroxyl groups, and any reduction is concomitant

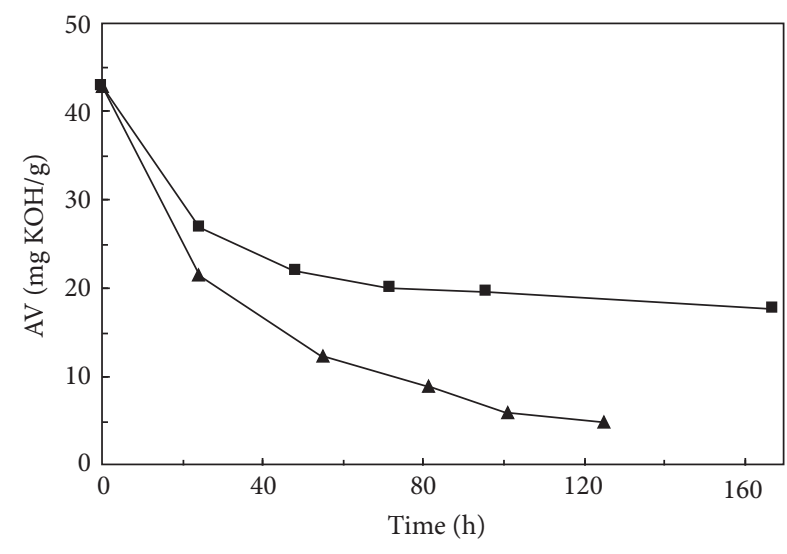

FIGURE 18: Influence of the reactor device on the production of PGPR using immobilized Rhizopus arrhizus lipase [66]. (ロ) openair reactor and $(\mathbf{\Lambda})$ vacuum reactor.

TABLE 8: Enzymatic PGPR characterization values compared with those established by the European Directive 2008/84/EC.

\begin{tabular}{lcc}
\hline & $\begin{array}{c}\text { European Commission } \\
\text { Directive [56] }\end{array}$ & $\begin{array}{c}\text { Enzymatic } \\
\text { PGPR }\end{array}$ \\
\hline $\begin{array}{l}\text { Acid value }(\mathrm{mg} \mathrm{KOH} / \mathrm{g}) \\
\text { Hydroxyl value }\end{array}$ & $\leq 6$ & 4.9 \\
$\begin{array}{l}\text { mg KOH/g) } \\
\text { Refractive index }[n]^{65}\end{array}$ & $80-100$ & 82.77 \\
\hline
\end{tabular}

with a decrease in AV because one of each is consumed when an ester linkage is formed [93]. When the PR/PG-3 mass ratio used is lower than 12 , both requirements cannot be fulfilled because, even if all the acid groups react, and AV is close to zero, too many hydroxyl groups remain unreacted (HV $>100 \mathrm{mg} \mathrm{KOH} / \mathrm{g}$ ). On the other hand when the PR/PG-3 ratio is too high, the final product will contain too many acid groups or too few hydroxyl groups. Therefore, the substrate mass ratio (PR/PG-3) in all the experiments was maintained constant at a value of 15 , which means that three of the five hydroxyl groups of the polyglycerol could be esterified.

Other optimal reaction conditions were determined: $40^{\circ} \mathrm{C}$ and no additional water added to the reactor at the beginning of the reaction but only that soaked in the immobilized derivative [66].

Production of PGPR in a Vacuum Reactor. In all the experiments described until now the final acid value was far from this objective, which means that the equilibrium has to be shifted towards the esterification pathway. This can be done by using a more anhydrous medium. On the other hand, the crucial importance of the amount of water in the reaction medium is illustrated by the poor reproducibility of the processes taking place in open reactors, since this parameter is heavily influenced by seasonality and weather conditions. This is particularly important in our case, when the final purpose is the production of the additive on an industrial scale, which requires rigorous standardization. For this reason, a high performance reactor was tested for PGPR 


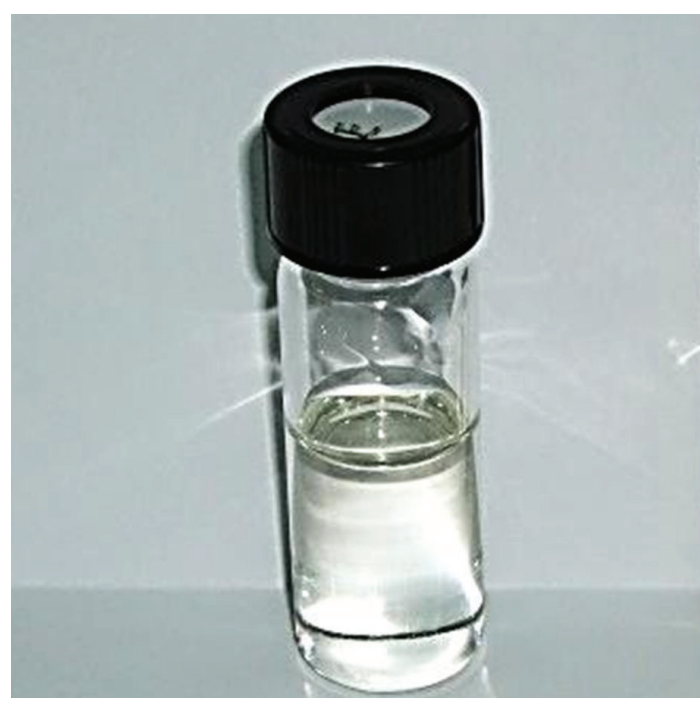

FIgURE 19: Photograph of enzymatic PGPR [94].

production. The reactor is thermostated, it can work in a wide range of pressures, and is also able to mix to the reaction medium in accordance with its high viscosity. In this reactor the amount of water can be manipulated through the pressure and the entry of dry nitrogen, making it independent of environmental conditions [66].

Figure 18 shows the results of PGPR synthesis using immobilized lipase in the high performance reactor. This reactor provides a controlled atmosphere that facilitates the adjusting of the water content in the reactor medium. In the tested conditions, the water content in the reaction medium was established at around 2000 ppm (Karl-Fisher) after $10 \mathrm{~h}$ (a totally anhydrous medium would lead to enzyme inactivation). In these conditions, the objective of the European Commission Directive was attained after $100 \mathrm{~h}$ (AV $=5.9 \mathrm{mg} \mathrm{KOH} / \mathrm{g}$ ) but even lower values can be reached at longer times (after $125 \mathrm{~h}$ the AV was $4.9 \mathrm{mg} \mathrm{KOH} / \mathrm{g}$ ). Although Figure 18 only depicts one curve corresponding to the vacuum reactor, several experiments were carried out in identical conditions and the same results were obtained [66].

Figure 18 also reveals the enormous difference between PGPR biosynthesis in open-air and vacuum reactors. Both esterification processes were made with the same amount of substrate, immobilized derivative, and initial amount of water. In the atmospheric reactor the target was not reached even after one week, whereas in the vacuum reactor PGPR was ready after $100 \mathrm{~h}$.

The PGPR produced by biocatalytic synthesis fulfills all the requirements of the European Commission Directive, as shown in Table 8.

Finally, it is important to note that the organoleptic properties of the enzymatic PGPR are better than those showed by other commercial PGPRs. In Figure 19 a photograph of the enzymatic PGPRs is shown, where the absence of color can be observed [94]. This fact, together with the properties displayed in Table 8 , makes the enzymatic PGPR a valuable alternative to the chemical synthesized one.
Nowadays the general applicability of this enzymatic method to obtain different fatty acid esters is under study.

\section{Acknowledgments}

The author wishes to express her deep gratitude to the members of the research group "Análisis y Simulación de Procesos Químicos, Bioquímicosy de Membrana”, Universidad de Murcia, España, without whose knowledge and assistance this article would not have been successful. This work was partially support by a grant CTQ2011-24091, MICINN, Spain.

\section{References}

[1] R. MacRae, R. K. Robinson, and M. J. Sadler, Eds., Encyclopaedia of Food Science, Food Technology, and Nutrition, vol. 8, Academic Press, New York, NY, USA, 1993.

[2] Y. H. Hui, Ed., Encyclopedia of Food Science and Technology, vol. 4, John Wiley \& Sons, New York, NY, USA, 1992.

[3] P. J. Fellows, Food Processing Technology: Principles and Practices, Woodhead Publishing Limited, Cambridge, UK, 3rd edition, 2009.

[4] A. L. Branen, P. M. Davidson, S. Salminen, and J. Thorngate, Eds., Food Additives, Taylor \& Francis, Boca Raton, Fla, USA, 2001.

[5] T. E. Furia, Ed., Handbook of Food Additives, vol. 2, CRC Press, New York, NY, USA, 2nd edition, 1980.

[6] J. A. Maga and A. T. Tu, Eds., Food Additive Toxicology, Taylor \& Francis, London, UK, 1995.

[7] J. S. Smith, Ed., Food Additive User's Handbook, Springer, New York, NY, USA, 1991.

[8] Codex alimentarius, 2012, http://www.codexalimentarius.org.

[9] H. Moonen and H. Bas ", "Mono- and diglycerides," in Emulsifiers in Food Technology, R. J. Whitehurst, Ed., John Wiley \& Sons, New York, NY, USA, 2008.

[10] NPCS Board of Consultants \& Engineers, The Complete Book on Emulsifiers With Uses, Formulae and Processes, 2007.

[11] G. L. Hasenhuettl and R. W. Hartel, Eds., Emulsifiers and Their Applications, Springer, New York, NY, USA, 2008.

[12] C. Stauffer, Emulsifiers, Eagan Press, 1999.

[13] N. Garti, "Food emulsifiers. structure-reactivity relationships, design, and applications," in Physical Properties of Lipids, A. G. Marangoni and S. S. Narine, Eds., Taylor \& Francis, London, UK, 2002.

[14] C. C. Cai, "Emulsifiers used in food applications, focusing on the meat processing industry," Palsgaard Technical Paper, 2011.

[15] C. E. Stauffer, "Emulsifiers for the food industry," in Bailey'a Induatrial Oil and Fat Producta, F. Shahidi, Ed., John Wiley \& Sons, New York, NY, USA, 2005.

[16] M. Gómez, S. Del Real, C. M. Rosell, F. Ronda, C. A. Blanco, and P. A. Caballero, "Functionality of different emulsifiers on the performance of breadmaking and wheat bread quality," European Food Research and Technology, vol. 219, no. 2, pp. 145-150, 2004.

[17] L. Stampfli and B. Nersten, "Emulsifiers in bread making," Food Chemistry, vol. 52, pp. 353-360, 1995.

[18] Z. Kohajdová, J. Karovičová, and Š. Schmidt, "Significance of emulsifiers and hydrocolloids in bakery industry," Acta Chimica Slovaca, vol. 2, pp. 46-461, 2009. 
[19] R. T. McIntyre, “Polyglycerol esters," Journal of the American Oil Chemists' Society, vol. 56, pp. A835-A840, 1979.

[20] M. F. Stewart and E. J. Hughes, "Polyglycerol esters as food additives," Process Biochemistry Journal, vol. 7, pp. 27-28, 1972.

[21] N. Garti, G. F. Remon, and B. Zaidman, "Polyglycerol esters of vegetable oils," Tenside, Surfactants, Detergents, vol. 23, no. 6, pp. 320-324, 1986.

[22] N. Garti, A. Aserin, and B. Zaidman, "Polyglycerol esters: optimization and techno-economic evaluation," Journal of the American Oil Chemists' Society, vol. 58, no. 9, pp. 878-883, 1981.

[23] "Polyglycerols in food applications," Application data sheet. Solvay Chemicals International.

[24] J. Holstborg, B. V. Pedersen, N. Krog, and S. K. Olesen, "Physical properties of diglycerol esters in relation to rheology and stability of protein-stabilised emulsions," Colloids and Surfaces B, vol. 12, no. 3-6, pp. 383-390, 1999.

[25] S. K. Olesen and N. Krog, "Phase behaviour of new food emulsifiers and their application," in Oils and Fats in Food Applications: Proceedings of the Food Applications Session of the 22nd Congress of the International Society of Fats Research (ISF), Kuala Lumpur, Malaysia, 7-12 September 1997, K. G. Berger, Ed., 1997.

[26] A. Sein, J. A. Verheij, and W. G. M. Agterof, "Rheological characterization, crystallization, and gelation behavior of monoglyceride gels," Journal of Colloid and Interface Science, vol. 249, no. 2, pp. 412-422, 2002.

[27] N. Krog, "Crystallization properties and lyotropic phase behavior of food emulsifiers," in Crystallization Processes in Fats and Lipid Systems, N. Garti and K. Sato, Eds., Taylor \& Francis, London, UK, 2001.

[28] P. Seiden and J. B. Martin, "Process for preparing polyglycerol," US 3,968,169, 1976.

[29] “Polyglycerols-general overview," Product data sheet. Solvay Chemical International.

[30] V. Norn, "Polyglycerol esters," in Emulsifiers in Food Technology, R. J. Whitehurst, Ed., 2008.

[31] T. Ushikusa, T. Maruyama, I. Nhya, and M. Okada, "Pyrolysis behaviors and thermostability of polyglycerols and polyglycerol fatty acid esters," Journal of the Japan Oil Chemists' Society, vol. 39, no. 5, pp. 314-320, 1990.

[32] "Polyglycerols for ester production," Application data sheet. Solvay Chemical International.

[33] F. van de Velde, F. Weinbreck, M. W. Edelman, E. Van Der Linden, and R. H. Tromp, "Visualisation of biopolymer mixtures using confocal scanning laser microscopy (CSLM) and covalent labelling techniques," Colloids and Surfaces B, vol. 31, no. 1-4, pp. 159-168, 2003.

[34] I. Kobayashi, X. Lou, S. Mukataka, and M. Nakajima, "Preparation of monodisperse water-in-oil-in-water emulsions using microfluidization and straight-through microchannel emulsification," Journal of the American Oil Chemists' Society, vol. 82, no. 1, pp. 65-71, 2005.

[35] J. Su, J. Flanagan, Y. Hemar, and H. Singh, "Synergistic effects of polyglycerol ester of polyricinoleic acid and sodium caseinate on the stabilisation of water-oil-water emulsions," Food Hydrocolloids, vol. 20, no. 2-3, pp. 261-268, 2006.

[36] J. Surh, G. T. Vladisavljević, S. Mun, and D. J. McClements, "Preparation and characterization of water/oil and water/oil/ water emulsions containing biopolymer-gelled water droplets," Journal of Agricultural and Food Chemistry, vol. 55, no. 1, pp. 175-184, 2007.
[37] A. Benichou, A. Aserin, and N. Garti, "Polyols, high pressure, and refractive indices equalization for improved stability of W/O emulsions for food applications," Journal of Dispersion Science and Technology, vol. 22, no. 2-3, pp. 269-280, 2001.

[38] S. Mun, Y. Choi, S. J. Rho, C. G. Kang, C. H. Park, and Y. R. Kim, "Preparation and characterization of water/oil/water emulsions stabilized by polyglycerol polyricinoleate and whey protein isolate," Journal of Food Science, vol. 75, no. 2, pp. E116-E125, 2010.

[39] D. Sağlam, P. Venema, R. de Vries, L. M. C. Sagis, and E. van der Linden, "Preparation of high protein micro-particles using two-step emulsification," Food Hydrocolloids, vol. 25, no. 5, pp. 1139-1148, 2011.

[40] R. Wilson, B. J. van Schie, and D. Howes, "Overview of the preparation, use and biological studies on polyglycerol polyricinoleate (PGPR)," Food and Chemical Toxicology, vol. 36, no. 9-10, pp. 711-718, 1998.

[41] E. Flack, "Margarines and spreads," in Food Emulsifiers and Their Applications, G. L. Hasenhuettl and R. W. Hartel, Eds., Springer, New York, NY, USA, 1997.

[42] S. M. Clegg, A. K. Moore, and S. A. Jones, "Low-fat margarine spreads as affected by aqueous phase hydrocolloids," Journal of Food Science, vol. 61, no. 5, pp. 1073-1079, 1996.

[43] B. Schantz and H. Rohm, "Influence of lecithin-PGPR blends on the rheological properties of chocolate," Lebensm-wiss $u$ Technol, vol. 38, no. 1, pp. 41-45, 2005.

[44] H. F. Banford, K. J. Gardiner, G. R. Howat, and A. F. Thomson, "The use of polyglycerol polyricinoleate in chocolate," Confectionery Production, vol. 36, pp. 359-365, 1970.

[45] P. Lonchampt and R. W. Hartel, "Fat bloom in chocolate and compound coatings," European Journal of Lipid Science and Technology, vol. 106, pp. 241-274, 2004.

[46] R. Peschar, M. M. Pop, D. J. A. de Ridder, J. B. van Mechelen, R. A. J. Driessen, and H. Schenk, "Crystal structures of 1,3distearoyl-2-oleoylglycerol and cocoa butter in the $\beta(\mathrm{V})$ phase reveal the driving force behind the occurrence of fat bloom on chocolate," Journal of Physical Chemistry B, vol. 108, no. 40, pp. 15450-15453, 2004.

[47] H. Schenk and R. Peschar, "Understanding the structure of chocolate," Radiation Physics and Chemistry, vol. 71, pp. 829-835, 2004.

[48] R. Wilson and M. Smith, "A three-generation reproduction study on polyglycerol polyricinoleate (PGPR) in wistar rats," Food and Chemical Toxicology, vol. 36, no. 9-10, pp. 739-741, 1998.

[49] R. Wilson and M. Smith, "Human studies on polyglycerol polyricinoleate (PGPR)," Food and Chemical Toxicology, vol. 36, no. 9-10, pp. 743-745, 1998.

[50] R. Wilson, B. H. Doell, W. Groger, J. Hope, and J. B. M. Gellatly, "The physiology of liver enlargement," in Metabolic Aspects of Food Safety, F. J. C. Roe, Ed., 1970.

[51] D. Howes, R. Wilson, and C. T. James, "The fate of ingested glyceran esters of condensed castor oil fatty acids [polyglycerol polyricinoleate (PGPR)] in the rat," Food and Chemical Toxicology, vol. 36, no. 9-10, pp. 719-738, 1998.

[52] J. Philp McL, "Evaluation of the safety of foods," Proceedings of the Nutrition Society, vol. 40, pp. 47-56, 1981.

[53] JECFA, "17th Report on the Joint FAO/WHO Expert Committee on Food Additives," 1973, http://www.fao.org/.

[54] "Report from the Commission on Dietary Food Additive Intake in the European Union," Commission of the European Communities, Brussels, Belgium, 2001. 
[55] Directive No 95/2/EC of the European Parliament and of the Council of 20 February 1995 on food additives other than colours and sweeteners.

[56] Commission Directive 2008/84/EC of the European Parliament and of the Council of 27 August 2008 laying down specific purity criteria on food additives other than colours and sweeteners.

[57] P. Denecke, G. Börner, and V. V. Allmen, "Method of preparing polyglycerol polyricinoleic fatty acid esters," GB2073232A, 1981.

[58] S. N. Modak and J. G. Kane, "Studies in estolides. I. Kinetics of estolide formation and decomposition," Journal of the American Oil Chemists' Society, vol. 42, pp. 428-232, 1965.

[59] K. T. Achaya, "Chemical derivatives of castor oil," Journal of the American Oil Chemists' Society, vol. 48, no. 11, pp. 758-763, 1971.

[60] R. Tenore, "Process for the direct manufacture of polyglycerol polyricinoleate," WO 2007/027447 A1, 2007.

[61] A. Manresa, A. Bódalo, J. L. Gómez et al., "Method for obtaining polyglycerol polyricinoleate," WO 2088/031908 A1, 2008.

[62] A. Bódalo, J. Bastida, M. F. Máximo, M. C. Montiel, and M. D. Murcia, "Enzymatic biosynthesis of ricinoleic acid estolides," Biochemical Engineering Journal, vol. 26, pp. 155-158, 2005.

[63] A. Bódalo, J. Bastida, M. F. Máximo, M. C. Montiel, M. Gómez, and M. D. Murcia, "Production of ricinoleic acid estolide with free and immobilised lipase from Candida rugosa," Biochemical Engineering Journal, vol. 39, pp. 450-456, 2008.

[64] A. Bódalo, J. Bastida, M. F. Máximo, M. C. Montiel, M. D. Murcia, and S. Ortega, "Influence of the operating conditions on lipase-catalysed synthesis of ricinoleic acid estolides in solventfree systems," Biochemical Engineering Journal, vol. 44, no. 2-3, pp. 214-219, 2009.

[65] A. Bódalo, J. Bastida, M. F. Máximo, M. C. Montiel, M. Gómez, and S. Ortega, "Screening and selection of lipases for the enzymatic production of polyglycerol polyricinoleate," Biochemical Engineering Journal, vol. 46, pp. 217-222, 2009.

[66] J. L. Gómez, J. Bastida, M. F. Máximo, M. C. Montiel, M. D. Murcia, and S. Ortega, "Solvent-free polyglycerol polyricinoleate synthesis mediated by lipase from Rhizopus arrhizus," Biochemical Engineering Journal, vol. 54, pp. 111-116, 2011.

[67] N. N. Gandhi, "Applications of lipase," Journal of the American Oil Chemists' Society, vol. 74, pp. 621-634, 1997.

[68] D. G. Hayes and R. Kleiman, "Lipase-catalyzed synthesis and properties of estolides and their esters," Journal of the American Oil Chemists' Society, vol. 72, no. 11, pp. 1309-1316, 1995.

[69] D. G. Hayes, "The catalytic activity of lipases toward hydroxyl fatty acids. A review," Journal of the American Oil Chemists' Society, vol. 73, pp. 543-549, 1996.

[70] F. Ergan, M. Trani, and G. André, "Production of glycerides from glycerol and fatty acid by immobilized lipases in nonaqueous media," Biotechnology and Bioengineering, vol. 35, no. 2, pp. 195-200, 1990.

[71] D. Charlemagne and M. D. Legoy, "Enzymatic synthesis of polyglycerol-fatty acid esters in solvent-free system," Journal of the American Oil Chemists' Society, vol. 72, pp. 61-65, 1995.

[72] G. W. V. Cave, C. L. Raston, and J. L. Scott, "Recent advances in solventless organic reactions: towards benign synthesis with remarkable versatility," Chemical Communications, no. 21, pp. 2159-2169, 2001.

[73] G. Hills, "Industrial use of lipases to product fatty acid esters," European Journal of Lipid Science and Technology, vol. 105, pp. 601-607, 2003.
[74] P. T. Anastas and J. C. Warner, Green Chemistry: Theory and Practice, Oxford University Press, New York, NY, USA, 1998.

[75] C. Yamaguchi, M. Akita, S. Asaoka, and F. Osada, "Enzymatic manufacture of castor oil fatty acid estolides," JP 8916591, 1988.

[76] C. Yamaguchi, A. Tooyama, S. Asaoka, and F. Osada, "Manufacture of glycerin-free estolides from castor oil with lipase," JP 9013387, 1989.

[77] C. Yamaguchi et al., “Production of estolide,” JP 5211878, 1993.

[78] Y. Yoshida et al., "Production of estolide from ricinoleic acid," JP 5304966, 1993.

[79] Y. Yoshida, M. Kawase, C. Yamaguchi, and T. Yamane, "Enzymatic synthesis of estolides by a bioreactor," Journal of the American Oil Chemists'Society, vol. 74, no. 3, pp. 261-267, 1997.

[80] Y. Yoshida, M. Kawase, C. Yamaguchi, and T. Yamane, "Synthesis of estolides with immobilized lipase," Yukagaku, vol. 44, pp. 328-333, 1995.

[81] A. Bódalo, E. Gómez, J. L. Gómez, J. Bastida, M. F. Máximo, and F. Díaz, "A comparison of different methods of $\beta$-galactosidase immobilization," Process Biochemistry Journal, vol. 26, pp. 349-353, 1991.

[82] J. L. Gómez, A. Bódalo, E. Gómez, J. Bastida, A. M. Hidalgo, and M. Gómez, "Immobilisation of peroxidase on glass beads: an improved alternative for phenol removal," Enzyme and Microbial Technology, vol. 39, pp. 2016-2022, 2006.

[83] E. F. Hartree, "Protein determination and improved modification of the Lowry's method which gives a linear photometric response," Analytical Biochemistry, vol. 42, pp. 422-427, 1973.

[84] ASTM D974-06, "Standard test method for acid and base number by color indicator titration".

[85] J. C. Santos, G. F. M. Nunes, A. B. R. Moreira, V. H. Perez, and H. F. de Castro, "Characterization of Candida rugosa lipase immobilized on poly(N-methylolacrylamide) and its application in butyl butyrate synthesis," Chemical Engineering and Technology, vol. 30, no. 9, pp. 1255-1261, 2007.

[86] L. Guo, Z. Zhang, Y. Zhu, J. Li, and Z. Xie, "Synthesis of polysiloxane-polyester copolymer by lipase-catalyzed polycondensation," Journal of Applied Polymer Science, vol. 108, no. 3, pp. 1901-1907, 2008.

[87] H. T. Dang, O. Obiri, and D. G. Hayes, "Feed batch addition of saccharide during saccharide-fatty acid esterification catalyzed by immobilized lipase: time course, water activity, and kinetic model," Journal of the American Oil Chemists' Society, vol. 82, no. 7, pp. 487-493, 2005.

[88] M. Goldberg, D. Thomas, and M. D. Legoy, "The control of lipase-catalysed transesterification and esterification reaction rates. Effects of substrate polarity, water activity and water molecules on enzyme activity," European Journal of Biochemistry, vol. 190, no. 3, pp. 603-609, 1990.

[89] A. R. M. Yahya, W. A. Anderson, and M. Moo-Young, "Ester synthesis in lipase catalysed reactions," Enzyme and Microbial Technology, vol. 23, pp. 438-450, 1998.

[90] A. M. Klibanov, "Enzymatic catalysis in anhydrous organic solvents," Trends in Biochemical Sciences, vol. 14, no. 4, pp. 141-144, 1989.

[91] “Sigma Aldrich catalog," En, http://www.sigmaaldrich.com/.

[92] Y. Yesiloglu, "Utilization of bentonite as a support material for immobilisation of Candida rugosa lipase," Process Biochemistry Journal, vol. 40, pp. 2155-2159, 2005.

[93] Committee on Food Chemicals Codex, Food and Nutrition Board, and Institute of Medicine, Food Chemicals Codex, 5th edition, 2004. 
[94] S. Ortega Requena, Síntesis biocatalítica de polirricinoleato de poliglicerol [Ph.D. thesis], University of Murcia, Murcia, Spain, 2012. 

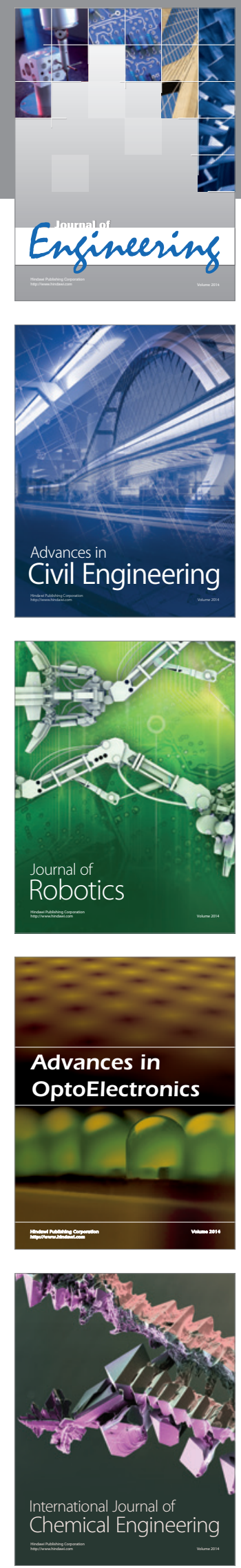

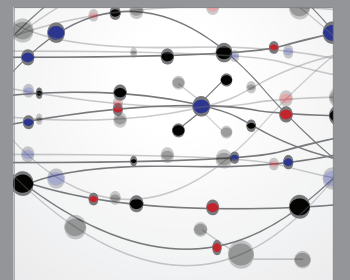

The Scientific World Journal
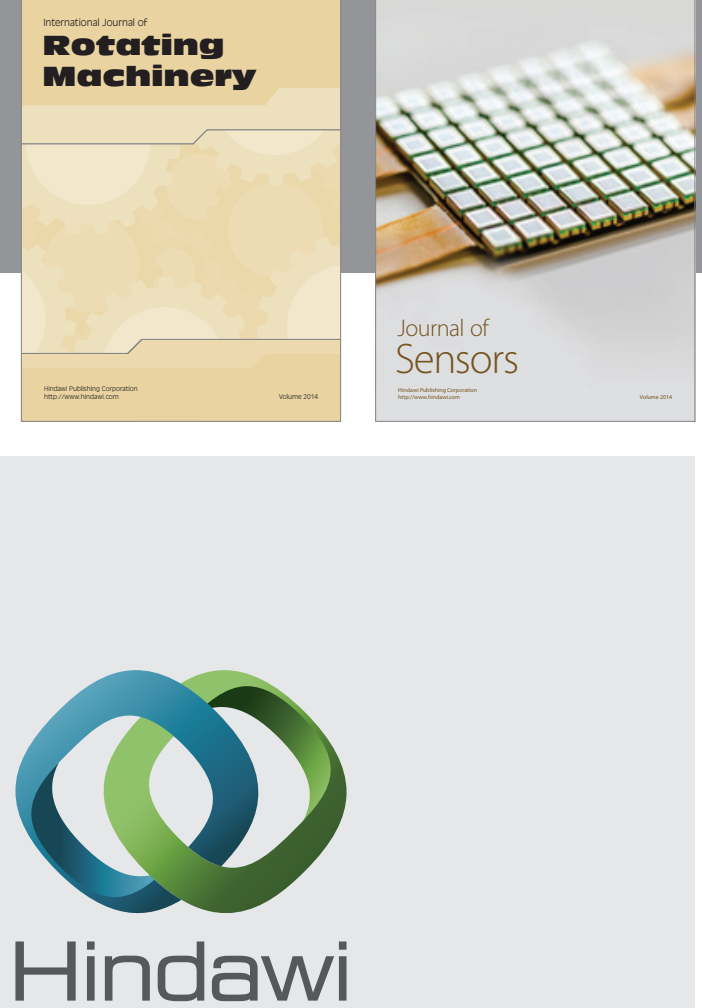

Submit your manuscripts at http://www.hindawi.com
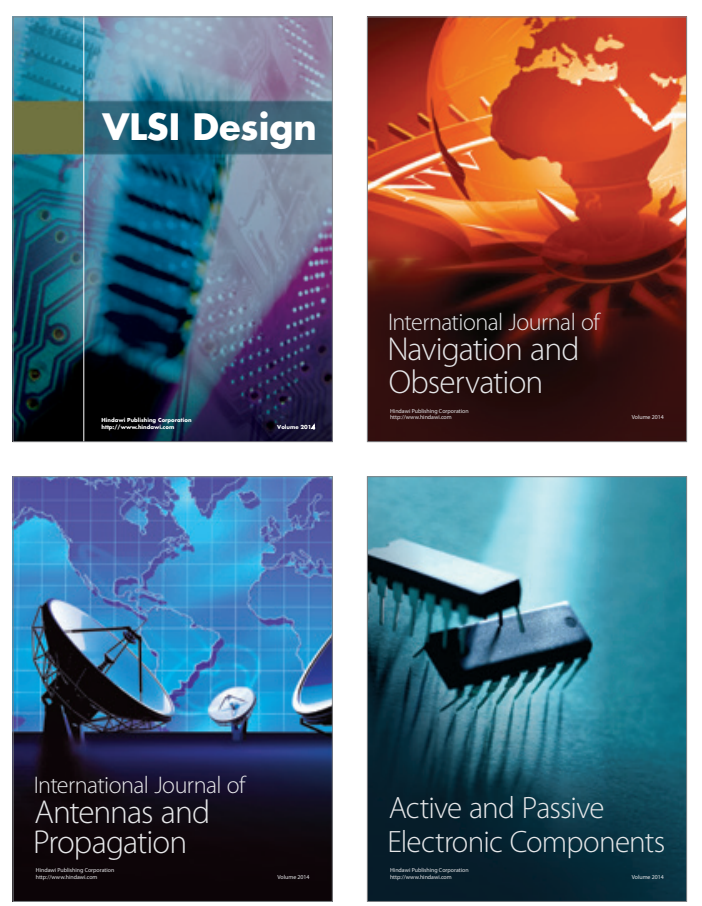
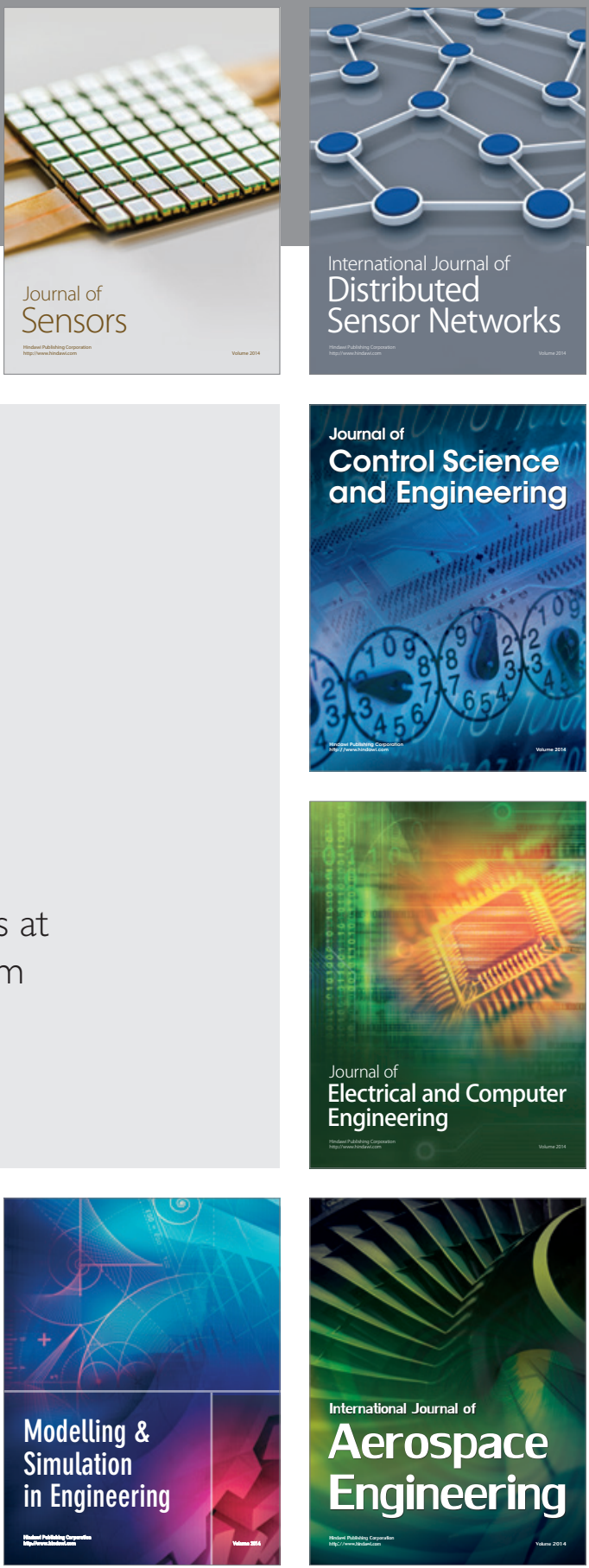

Journal of

Control Science

and Engineering
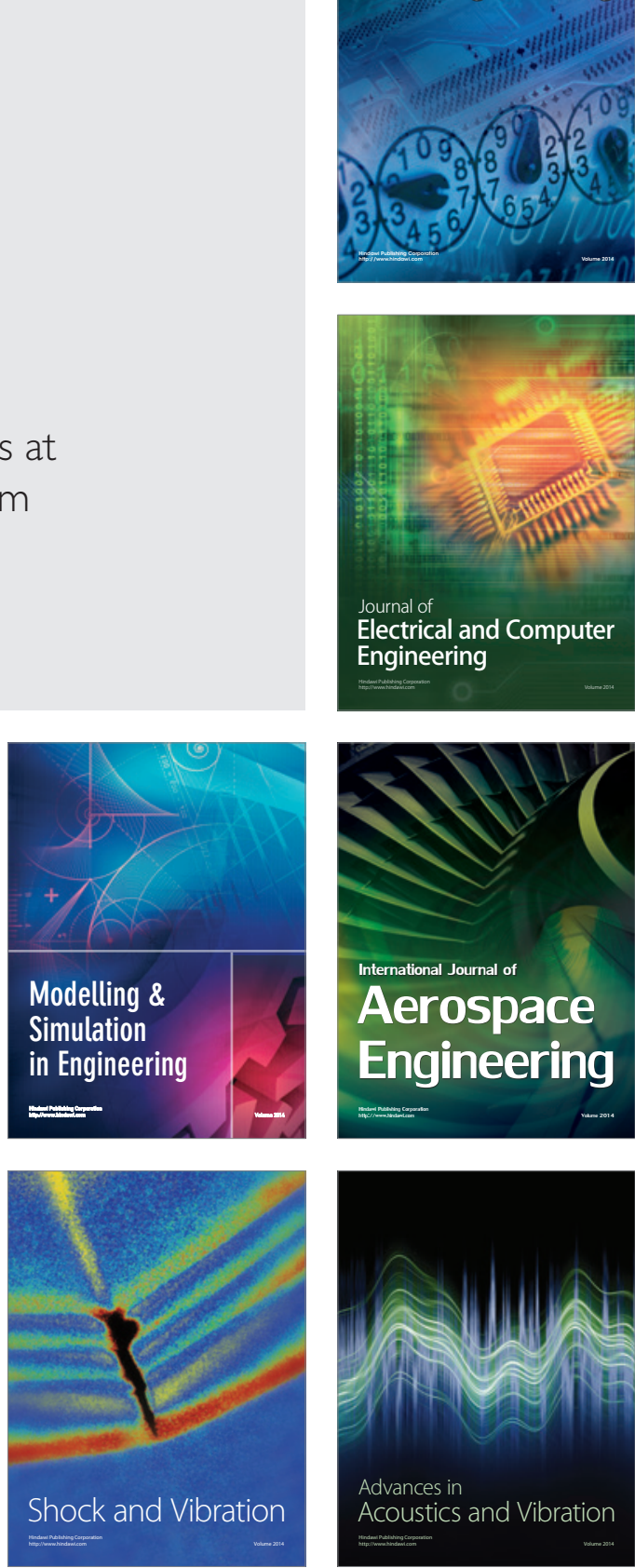